Silence superoxide dismutase 1 (SOD1): a promising therapeutic target for amyotrophic lateral sclerosis (ALS)

Elena Abati, Nereo Bresolin, Giacomo Comi \& Stefania Corti 


\section{Silence superoxide dismutase 1 (SOD1): a promising therapeutic target for amyotrophic lateral sclerosis (ALS)}

Elena Abati ${ }^{1}$, Nereo Bresolin ${ }^{1,2}$ Giacomo Comi ${ }^{1,2}$ and Stefania Corti ${ }^{1,2,3}$

${ }^{1}$ Department of Pathophysiology and Transplantation (DEPT), Dino Ferrari Centre, Neuroscience Section, University of Milan, Milan, Italy.

${ }^{2}$ Foundation IRCCS Ca' Granda Ospedale Maggiore Policlinico, Neurology Unit, Milan, Italy.

Corresponding author: Stefania Corti, Department of Pathophysiology and Transplantation (DEPT), Dino Ferrari Centre, Neuroscience Section, Neurology Unit, Foundation IRCCS Ca' Granda Ospedale Maggiore Policlinico, University of Milan, Milan, Italy 


\begin{abstract}
Introduction: Amyotrophic lateral sclerosis (ALS) is a progressive and incurable neurodegenerative disorder that targets upper and lower motor neurons and leads to fatal muscle paralysis. Mutations in the superoxide dismutase 1 (SOD1) gene are responsible for $15 \%$ of familial ALS cases, but several studies have indicated that SOD1 dysfunction may also play a pathogenic role in sporadic ALS. SOD1 induces numerous toxic effects through the pathological misfolding and aggregation of mutant SOD1 species, hence a reduction of the levels of toxic variants appears to be a promising therapeutic strategy for SOD1-related ALS. Several methods are used to modulate gene expression in vivo; these include RNA interference, antisense oligonucleotides (ASOs) and CRISPR/Cas9 technology.
\end{abstract}

Areas covered:_This paper examines the current approaches for gene silencing and the progress made in silencing SOD1 in vivo. It progresses to shed light on the key results and pitfalls of these studies and highlights the future challenges and new perspectives for this exciting research field.

Expert Opinion:-Gene silencing strategies targeting SOD1 may represent effective approaches for familial and sporadic ALS-related neurodegeneration; however, the risk of off-target effects must be minimized, and effective and minimally invasive delivery strategies should be fine-tuned.

Keywords: amyotrophic lateral sclerosis; ALS; superoxide dismutase 1; SOD1; gene silencing; RNA interference; antisense oligonucleotides; CRISPR; Cas9. 


\section{Article Highlights}

- Autosomal dominant mutations in the superoxide dismutase 1 (SOD1) gene, which encodes a free radical scavenger protein, are responsible for $15 \%$ of familial ALS cases.

- Mutant SOD1 exerts its toxic effect via pathological misfolding and aggregation, which has also been shown to occur in sporadic ALS.

- SOD1 aggregates may induce the spread of disease within the CNS through seeded aggregation and a prionlike transmission mechanism.

- Gene silencing can be achieved through different techniques, namely, antisense oligonucleotides (ASOs), RNA interference (RNAi) with small RNAs (miRNAs, shRNAs, and siRNAs) and CRISPR/Cas9 gene editing.

- ASOs do not require delivery systems, whereas RNAi- and CRISPR/Cas9-based tools need to be paired with viral vectors, the most commonly used being retroviruses, lentiviruses, adenoviruses and adeno-associated viruses.

- ASOs, AAV-delivered shRNAs and miRNAs and SOD1-targeted CRISPR/Cas9 systems have been tested in SOD1 mouse models with generally satisfying results. ASO-based therapy was shown to exhibit a good safety profile in humans in a phase I clinical trial and a phase I trial of an SOD1-directed miRNA construct will start soon.

- The most significant concerns regarding these therapeutic strategies include the risk of off-target effects, reduced allele specificity resulting in dangerous wild-type SOD1 inhibition, and the risk of immune activation.

- Future attempts to overcome these challenges may take advantage of gene knockout-and-replace approaches and nanoengineered delivery tools. 


\section{Introduction}

Amyotrophic lateral sclerosis (ALS) is a fatal motoneuronal disorder that causes progressive degeneration of upper and lower motor neurons in the primary motor cortex, brainstem, and spinal cord [1]. The degeneration and loss of motor neurons cause progressive weakness and atrophy of skeletal muscles, which usually progress to paralysis and death within 3 to 5 years [1]. Currently, no effective therapy exists for this disease. ALS is defined as sporadic (sALS) when it occurs in individuals with no family history and is termed familial (fALS) when at least two people from the same family are affected. Sporadic ALS represents $85-90 \%$ of all cases and has a median age of onset ranging from 58-63 years [1-3]. Familial ALS accounts for the remaining 10-15\% of cases and has a slightly younger age of onset (47-53 years) [2]; potential causative mutations have been identified in more than 50 genes. The most commonly mutated genes, accounting for almost $75 \%$ of fALS cases, are C9orf72, TARDBP, FUS and SOD1 [1]. Dominantly inherited mutations in the SOD1 gene were the first to be described and are linked to $15 \%$ of fALS cases [4]. Over 180 genetic variants of SOD1 have been identified in patients with ALS (http://alsod.iop.kcl.ac.uk/; http://databrowser.projectmine.com; http://alskp.org) [5-8]. The vast majority of pathogenic variants are heterozygous; however, rare homozygous variants have been described $[9,10]$.

The SOD1 gene is located on chromosome 21q22.11 and encodes $\mathrm{Cu} / \mathrm{Zn}$ superoxide dismutase. The SOD1 protein acts as an antioxidant enzyme by converting two superoxide anions, which are byproducts of cellular respiration with oxidant action, into hydrogen peroxide and oxygen [11]. Human SOD1 forms a homodimer, with each monomer binding one zinc ion and one copper ion and carrying a disulfide bond. Full metalation and disulfide bonding enhance protein stability in the cytoplasm and favor dimerization $[12,13]$. These posttranslational modifications are essential for the acquisition of its catalytic properties. SOD1 maturation appears to be mediated by copper chaperone for superoxide dismutase (Ccs1), which seems to determine SOD1 activation through copper insertion and disulfide bond formation [14-16]; however, its exact role has not been firmly established (thoroughly reviewed in [17]). SOD1 is present both in the cytosol and in the mitochondrial intermembrane space and controls the levels of oxidizing species, which are mostly produced by the 
mitochondrial respiratory chain and NADPH oxidases [18-21]. The presence of mutant SOD1 protein (mutSOD1) is strongly linked to motor neuron diseases. The pathogenic mechanism seems to be a gain-of-function mechanism that involves the formation of toxic SOD1 aggregates, although the mechanisms underlying SOD1 aggregation and toxicity have not yet been completely elucidated. Although changes in the levels of enzyme activity were initially believed to be the primary pathogenic mechanism, it was observed that disease severity does not correlate with levels of dismutase activity [22]. Further insights come from the observation that while transgenic mice overexpressing the SOD1 protein present a typical ALS phenotype, SOD1null mice do not $[23,24]$. This finding, together with the autosomal dominant transmission of SOD1 mutations, suggests that a gain of toxic function of SOD1 is the main pathogenic hit. Therefore, it has been hypothesized that mutSOD1 may induce disease by adopting an unstable conformation, which is reflected by the failure of downstream pathways in several cell types within the CNS [25]. Furthermore, recent evidence supports the role of SOD1-mediated toxicity and oxidative damage in the pathogenesis of sALS [26-28].

\section{Molecular and cellular mechanisms of SOD1-mediated toxicity}

\section{1 $\underline{\text { SOD1 misfolding and toxicity in familial ALS with SOD1 mutation }}$}

As mentioned above, inherited SOD1 mutations may exert their detrimental effect by inducing toxic changes in protein conformation, which in turn may cause the formation of toxic aggregates that accumulate in mitochondria, thus disrupting several cellular processes, including scavenging of free radicals, protein quality control and controlled degradation, mitochondrial function, axonal transport, mRNA splicing and membrane excitation [29-32]. It was found that a short epitope located within the N-terminal region of mutSOD1 called the Derlin-binding region (DBR) binds with high specificity to the cytosolic carboxyl-terminal region of Derlin-1, an endoplasmic reticulum (ER)-resident protein [33], causing ER stress, a mechanism known to play a role in several neurodegenerative diseases, including ALS [34]. A specific monoclonal antibody directed against DBR (MS785) is able to discriminate mutSOD1 from wild-type SOD1 (wtSOD1) and nontoxic mutants, suggesting that DBR might be masked in wtSOD1 and become exposed in mutSOD1 due to a pathogenic mutation-induced 
conformational change [35]. Furthermore, it was found that mutSOD1 is more prone to hydrophobicity than the wild-type protein and that different expositions of hydrophobic residues correlate with SOD1 aggregation levels [36]. These properties might also represent potential therapeutic targets, as reverting or inhibiting conformational alterations and/or changes in hydrophobicity might attenuate SOD1 toxicity. MutSOD1 monomers are believed to cause protein toxicity by reducing proteasome and chaperone activity and allowing abnormal protein-protein interactions [31]. Abnormalities in the chaperone system, such as the inhibition of protein disulfide isomerase (PDI), which is responsible for disulfide bond formation, have been shown to result in increased aggregate formation [37]. Indeed, increased inactivation of PDI by S-nitrosylation has been demonstrated to accompany disease progression in ALS [38]. Furthermore, another chaperone protein, macrophage migration inhibitory factor (MIF), has been found to inhibit the adhesion of mutSOD1 to mitochondria and consequent SOD1 accumulation within mitochondria and the ER, thus exerting protective effects [39]. Remarkably, MIF appears to be differentially expressed in astrocytes and motor neurons, with lower levels in motor neurons possibly explaining the increased susceptibility to noxious effects in ALS [39].

Aggregate formation in turn seems to disrupt different cellular pathways, causing mitochondrial dysfunction, excitotoxicity, oxidative stress, ER stress, axonal transport disruption, and intercellular prion-like propagation [32]. These findings highlight the potential benefit of therapies aimed at reducing the presence of mutant SOD1 aggregates, which might prove useful not only for fALS patients but also for sALS patients, as we will discuss in the following paragraph.

\section{$\underline{2.2}$ SOD1 misfolding and aggregation in sporadic ALS}

Notably, evidence suggests that the aggregation and spreading of misfolded proteins, including SOD1, is a key feature of sALS as well $[40,41]$. Indeed, wild-type SOD1 (wtSOD1) may gain a toxic function following changes in protein conformation induced by aberrant posttranslational mechanisms such as demetallation and overoxidation [26-28]. A common conformational epitope was detected in oxidized wtSOD1 and in fALS-linked mutant SOD1, but not in wtSOD1, and oxidized wtSOD1 was found to inhibit axonal transport in a manner similar to mutant SOD1 [28]. Furthermore, misfolded "mutant-like" SOD1 protein has been observed in 
postmortem spinal cord samples from sALS patients [42]. These observations may have implications for therapeutic translation. Indeed, it has been found that the knockdown of both wtSOD1 and mutSOD1 in astrocytes derived from sALS and fALS patients results in a reduction in MN-directed astrocytic toxicity [43]. SOD1 expression in different glial cell types, such as astrocytes [43,44], microglia [45] and oligodendrocytes [46], has been shown to contribute to ALS onset and progression, highlighting the pleiotropy observed in ALS.

\section{$\underline{2.3}$ Glia-mediated toxicity in ALS}

Non-cell-autonomous toxicity has been demonstrated in several rodent-derived and human-derived primary astrocyte lines (reviewed in [47]). In two cellular ALS models, for example, extensive death of primary spinal cord motoneurons and embryonic stem cell-derived motoneurons is induced when cells are cultured on astrocytes expressing human mutant SOD1 or exposed to conditioned medium derived from astrocytes expressing mutant SOD1 $[48,49]$. Moreover, mutant astrocytes have been found to exert a toxic effect on motor neurons through the secretion of a soluble Bax-dependent toxic factor [49], which was later found to induce an increase in membrane excitability and voltage-sensitive sodium channel activity [50,51]. Astrocytes also trigger motor neuron death in cocultures through the induction of mitochondrial dysfunction [52]. Another study demonstrated that human embryonic stem cell (hESC)-derived astrocytes activate inflammatory response pathways in the presence of SOD1 mutation and that this effect is reversed by treatment with antioxidant compounds [53]. Furthermore, induced pluripotent stem cell (iPSC)-derived astrocytes generated from fALS and sALS patients are able to trigger motor neuron death in coculture models [43,54,55]. In addition, the transplantation of mutant SOD1-expressing astrocyte precursors into the spinal cord of wild-type rats has been shown to result in cellular engraftment and subsequent mild and nonprogressive motor neuron degeneration [56].

\section{$\underline{2.4}$ Spreading of misfolded SOD1}

Seeded aggregation and cell-to-cell transmission are known properties of mutant SOD1 protein. Both mutSOD1 and wtSOD1 have the ability to seed the aggregation of the wild-type protein [57]. Exosomal transmission has been demonstrated for both mutant and wild-type SOD1 aggregates [57], while mutSOD1 can otherwise be 
released in neurosecretory vesicles through a chromogranin A- and B-mediated pathway [58]. Aggregates may then enter cells via micropinocytosis [59].

Furthermore, recent data seem to indicate that SOD1 aggregates may induce disease spreading within the CNS through a prion-like transmission mechanism. In transgenic murine models, SOD1 is able to form aggregate seeds that, upon inoculation into the spinal cord, spread along the neuraxis and initiate premature fatal motor neuron disease [60]. Moreover, spinal cord homogenates prepared from mice expressing mutSOD1 (SOD1-G93A and SOD1-G37R) induced severe pathology and an earlier onset of symptoms when directly injected into the spinal cords of mice carrying a mutated SOD1-G85R protein fused to yellow fluorescent protein (G85R-YFP mice) [61].

Taken together, these results might explain the initial focal manifestations of ALS and the subsequent contiguous spread that is usually observed in the clinical course of the disease. In addition, they provide a rational basis for silencing SOD1, as reducing the production of the mutant protein could potentially act directly on SOD1 toxicity, on the amount of aggregation, seeding and intercellular spreading, and on a variety of downstream pathways [32].

\section{Therapeutic silencing of SOD1 in ALS: Rationale and limits}

Since it was first discovered that gene expression can be directly modulated in vivo by exogenously delivered compounds, a new array of therapeutic opportunities has emerged. As discussed above, SOD1 represents an intriguing target for silencing strategies given its autosomal dominant inheritance and the evidence for the toxic role of the mutant protein. Conformational changes, seeded aggregation and possibly prion-like transmission seem to be the main causes of SOD1 dysfunction, while downstream degeneration is mediated by, among others, ER and oxidative stress, mitochondrial dysfunction and alterations in mRNA splicing and axonal transport [2932]. Furthermore, SOD1 seems to be implicated not only in fALS cases but also in sporadic cases, with mutant sALS-SOD1 sharing common epitopes with fALS-SOD1 [28]. Notably, the knockdown of SOD1 in astrocytes 
was shown to be able to attenuate neurotoxicity in an in vitro model, suggesting a possible beneficial role of SOD1-directed therapies in different types of cells in the CNS [43].

These findings notwithstanding, safety concerns arise from the controversial role of loss-of-function mutations in SOD1. Although a loss-of-function mechanism was previously thought to be the molecular basis of fALS $[62,63]$, evidence from studies in animal models have mostly rejected this hypothesis. Transgenic SOD1 knockout models do not show features of motor neuron disease, although they do present increased susceptibility to motor neuron loss after axonal damage, elevated oxidative stress and acceleration of age-related muscle loss [64-66]. Nevertheless, the current belief that SOD1 silencing does not exert pathogenic effects was challenged by a recent report of the first known case of inherited SOD1 deficiency [67]. The patient carried a homozygous truncated SOD1 variant that led to loss of enzymatic activity, as demonstrated by a functional assay, and to a phenotype characterized by hyperekplexia, ataxia, muscle hypotony and intellectual disability [67].

While the identification of this mutation supports the potential toxicity of a reduction in SOD1, this hypothesis was not confirmed by safety studies thus far. Animal and human trials of therapeutic silencing of SOD1 have not revealed significant safety concerns. The antisense oligonucleotide (ASO) ISIS 333611, which targets SOD1, was tested in the SOD1-G93A transgenic mouse model and caused a decrease in SOD1 mRNA and protein levels in the CSF and a slight prolongation of survival without inducing major side effects [68]. On these grounds, a human phase I clinical trial of intrathecally delivered ISIS 333611 was attempted; 21 patients received treatment, while 8 patients received sham treatment. Following treatment, SOD1 CSF concentrations were within $12 \%$ of the original value on average [69]. The most common adverse events were post lumbar puncture syndrome and back pain, which were likely related to the infusion procedure, and the rate did not differ between the treatment and placebo groups. Moreover, the number of adverse events did not increase with increasing doses of ISIS 333611. However, limited conclusions can be inferred from this study given the small study sample and the low treatment doses received by patients. Another silencing technique based on RNA interference (RNAi) that utilized a microRNA (miRNA) was tested in healthy nonhuman primates; the miRNA induced no serious adverse reactions and showed good tolerability and is therefore now ready to enter the clinical trial phase [70]. 
Overall, the effect of reducing or silencing SOD1 on motor neurons and other cell types in the CNS, as well as on functional neural networks, has not been completely clarified so far. Given the role of SOD1 in the metabolism of reactive oxygen species (ROS), its depletion could lead to the persistence of or even an increase in oxidative damage. As described above, findings from both animal and early human studies do not seem to indicate the presence of side effects linked to SOD1 depletion. However, this could be partly explained by the differences between animal and human physiology and by the low doses of silencing compounds used in the human trial. On the other hand, it can be argued that silencing efficiency is never complete, and that residual enzyme activity might be sufficient to prevent evident and immediate damage. It is difficult to predict whether a reduction in SOD1 can cause long-term complications related to chronic low-level oxidative stress and consequent inflammation. The preventative use of antioxidant compounds, such as $\mathrm{N}$-acetylcysteine, can counteract this potential side effect [71]. SOD1 mimetics have also been tested for their antioxidant properties against radiation-induced damage and have shown an acceptable safety profile [72]. Another potential strategy is the combination of gene silencing and replacement techniques, through which the reduction in the levels of endogenous SOD1 is balanced by the expression of an artificially delivered silencing-resistant SOD1 gene, as described by Xia and colleagues [73]. Further preclinical and clinical studies are needed to better characterize the impact of SOD1 silencing on neurons and glial cells and determine whether residual SOD1 activity might efficiently maintain SOD1-dependent physiological processes.

\section{Strategies for gene silencing}

In recent decades, increasing knowledge of the translational and posttranslational machinery has led to the identification and synthesis of molecules that are able to modulate gene expression by altering mRNA translation and pairing (Figure 1). These techniques include antisense oligonucleotides, RNAi and CRISPR/Cas9.

\section{$\underline{4.1}$ Antisense oligonucleotides (ASOs)}


ASOs are short (8-50 bp) synthetic single-stranded RNA molecules that trigger the RNase $\mathrm{H}<$ mediated cleavage of a complementary RNA target [74]. Several subclasses of ASOs have been created by altering the structure of ASOs, and morpholino phosphorodiamidate ASOs (PMOs), in which a morpholine ring in substituted for a ribose, have shown the highest stability and resistance to nucleases [74,75]. ASOs have been widely studied in the field of neurology, and ASO-mediated therapies were recently approved by the FDA for two neurological diseases: Spinraza for spinal muscular atrophy (SMA), a previously incurable motor neuron disease, and eteplirsen for Duchenne muscular dystrophy (DMD) [76,77]. A limitation of ASO technology is the reduced biodistribution and bioavailability of ASOs, which makes choosing an appropriate delivery site and method extremely important for reaching target sites to elicite the desired effects.

\section{$\underline{4.2}$ RNA interference}

The development of RNAi stemmed from the discovery that only a small fraction of the human genome is translated into protein products, while the vast majority (more than $85 \%$ ) is transcribed into noncoding RNAs (ncRNAs), the main function of which appears to be the regulation of gene expression.

Among ncRNAs, the most known and studied by far are miRNAs, small interfering RNAs (siRNAs) and short hairpin RNAs (shRNAs), which are small double-stranded RNA sequences that may originate endogenously (miRNAs) or exogenously (siRNAs and shRNAs) [78]. Small RNAs work by integrating into the RNA-induced silencing complex (RISC) and recognizing the complementary mRNA target sequence. Once the target is recognized, Argonaute (AGO) proteins, the effector proteins of the RISC, achieve silencing by blocking translation or by degrading the mRNA [78]. This endogenous pathway can be exploited by delivering exogenous compounds that are able to participate in this mechanism to silence target mRNAs (Figure 1). For instance, viral vectors that penetrate the nucleus can induce the transcription of either miRNAs or shRNAs, which are then processed via this pathway. siRNAs can be delivered as exogenous reagents and directly interact with the RISC complex. These nonendogenous silencing reagents have been termed "artificial" or "synthetic." 
RNAi holds great potential as a therapy for neurological diseases, and approved RNAi-based therapies include patisiran, an siRNA used for the treatment of amyloidosis [79,80]. The greatest limitations of RNAi are its poor stability, as all RNAi are susceptible to the action of serum nucleases, and off-target effects, which is the inappropriate silencing of nontarget mRNAs [78]. Different chemical modifications of the original RNA structure, such as modifications of the sugar moiety of siRNAs as a way to reduce instability and reduce immune system activation [78], have been tested for their ability to reduce these side effects. Backbone modification, such as replacement with phosphothioate and boranophosphate, may improve stability, and resist the actions of nucleases and cellular uptake $[81,82]$. In addition, modifications of siRNA terminal strands with cholesterol, folate or other peptides were investigated for their ability to aid in membrane crossing to the targeting specific cells or organs [83].

\subsection{CRISPR/Cas9}

The clustered regularly interspaced short palindromic repeats (CRISPR)/CRISPR-associated protein-9 nuclease (Cas9) system is an RNA-guided DNA editing tool derived from natural bacterial defense mechanisms that creates double-strand breaks (DSBs) in target sites in the genome, allowing for precise genome editing [84]. In bacteria, viral DNA sequences are recognized by two constructs, CRISPR targeting RNA (crRNA) and transactivating RNA (tracrRNA) [84]. Cas9 is a gene editing protein derived from Streptococcus pyogenes . In the CRISPR/Cas9 system, crRNA and tracrRNA are fused into a single guide RNA (sgRNA) that locates the target DNA sequence, while Cas9 is the gene editing effector. Within the sgRNA, there are two recognition sequences, one of which recognizes the complementary target sequences and the other of which, a photospacer adjacent motif (PAM), matches with the complementary PAM at the 3' end of the target sequence to initiate cleavage. These two processes aim to reduce offtarget effects, although they cannot abolish them completely. Different structural modifications, which were thoroughly reviewed previously [85], have been studied for their ability to further reduce off-target effects. 
Recently, two innovative treatments based on the modification of autologous T-cells with CRISPR-Cas9 technology, $\mathrm{CAR}<\mathrm{T}$ (chimeric antigen receptor engineered $\mathrm{T}$ cells) and $\mathrm{TCR}<\mathrm{T}(\mathrm{T}$ cell receptor engineered $\mathrm{T}$ cells), have been approved for cancer therapy [86].

\subsection{Delivery strategies for molecular therapies}

A considerable issue regarding molecular therapy is optimal delivery, as high intracellular entry is required to maximize clinical effects. In neurological diseases, an additional obstacle is the identification of the target site, as the high functional specialization of different CNS areas combined with low blood-brain barrier (BBB) permeability make the spreading of effector molecules difficult [87].

ASOs do not require associated delivery systems, but they are not able to cross the BBB; thus, they need to be injected into the CNS [88]. Conversely, RNAi therapy-, CRISPR-and gene therapy-based strategies require delivery tools [87]. Given their small dimensions, high lipophilicity and reduced binding to serum proteins, molecules such as polymeric nanoparticles (NPs) and lipid complexes might serve this function [87]. Nevertheless, viral vectors, particular retroviruses, lentiviruses, adenoviruses and adeno-associated viruses (AAVs), which are able to infect host cells and replicate through the host machinery (and are thus able to cross the BBB and easily reach target sites), are the most commonly used tools.

In the field of neurological diseases, the most widely used and studied vectors are AAV vectors due to their potential to infect both replicating cells, such as astrocytes, and nonreplicating cells, such as neurons, and their ability to ensure stable gene expression with each delivery. Furthermore, AAVs have a low immunogenic profile and show no pathogenicity [89]. Cell tropism of AAVs varies according to their capsid composition; thus, different serotypes can be distinguished based on their specific distribution. AAV2, AAV5, AAV8 and AAV9 are able to transfect neurons, while AAV5 and AAV1 are capable of transfecting astrocytes and oligodendrocytes as well [90,91].

AAV9 has been shown to have a unique ability to cross the BBB. Murine studies on the intravenous administration of AAV9 combined with green fluorescent protein (GFP) have shown diffuse distribution of GFP in the brains and spinal cords of newborn mice but scarce distribution mostly limited to astrocytes in adult mice [92]. Conversely, 
intrathecal administration leads to increased GFP expression [93,94], though limited to anterior horn alpha-motor neurons, while ventral horn interneurons appear to be transgene-negative [95]. Based on these results, Miyanohara and colleagues hypothesized the involvement of an additional regulatory barrier system (besides the BBB) that prevents the penetration of the virus into deeper spinal compartments from the intrathecal space and suggested that this system could be the pia mater. Thus, they studied the subpial (SP) delivery of AAV9-GFP or AAV9-RFP (red fluorescent protein) in adult rats and pigs, which resulted in a wider distribution of the transgene in the spinal parenchyma and descending and ascending axons [95]. A recent study also tested subpial delivery of AAV9-shRNAs in animals with satisfactory results [96]. Thus, SP delivery could represent a more powerful and efficient delivery method if adequately implemented. Currently, local laminectomy is required, making this delivery method unsuitable for clinical trials; however, the use of SP delivery could allow reduced frequency of administration.

The first AAV2-delivered gene therapy, voretigene neparvovec (AAV2-hRPE65v2), was approved in 2017 for RPE65-related retinal diseases [97]. Voretigene is administered by subretinal injection and delivers human RPE65 cDNA to retinal pigment epithelial cells. Furthermore, in 2019, onasemnogene abeparvovec (trade name Zolgensma), an AAV9-based gene therapy designed to deliver a functional copy of the human survival motor neuron (SMN) gene to motor neurons, was approved by the FDA for the treatment of SMA in patients aged <2 years [98]. A single injection resulted in significant improvements in survival in treated patients, who survived beyond 20 months of age and did not require ventilation until this point. Compared to controls, these patients also showed a slower decline in motor function and improved acquisition of motor milestones and thus developed a milder phenotype. Outcomes appeared to correlate positively with an earlier age of treatment administration. However, long-term follow-up studies are still needed to evaluate the degree of motor decline at later stages and the potential long-term complications.

Once the best vector for the selected therapy is chosen, another aspect to consider is the administration route. In the case of highly localized pathology, such as the substantia nigra in Parkinson's disease, the striatum in Huntington's disease and the cerebellum in spinocerebellar ataxia, local injection might be an effective method, at least in 
preclinical models, and ensure high transgene expression at the injection site. However, degeneration in ALS is characterized by a diffuse distribution along the neuraxis, including the cortex, brainstem and anterior horns of the spinal cord. Indeed, the injection of an shRNA-expressing AAV into the spinal cord results in reduced transduction and no clinical improvement in animals [99]. Other methods that has been tested is the injection of a vector into skeletal muscle, which causes subsequent internalization in peripheral nerves and retrograde transport, and direct injection into large peripheral nerves [100-102]. These techniques, however, have limited effect and are also difficult to translate into clinical practice given the high number of injections that are required. Furthermore, the high doses that are necessary would pose significant safety issues given their potential to cause both local and systemic immune reactions, a high risk of immunization and systemic off-target effects.

Another approach is intravenous administration. As described above, some AAV serotypes have the capacity to cross the BBB, and the intravenous route has been tested with conflicting results [102-106]. This method allows for repetitive administration given its noninvasive nature, but it is limited by low CNS penetrance with a concomitant risk of peripheral tissue transduction and immunogenicity.

Conversely, several groups have chosen to deliver constructs by intrathecal administration, which results in high overall cell transduction efficiency and good distribution along the neuraxis. However, intrathecal delivery is invasive and might not be suitable for repeated dosing, although it allows for satisfactory diffusion within the CNS. Finally, as mentioned above, another delivery method is subpial administration, which was successfully tested in animal models [96].

All these methods have been exploited by researchers (Table 1), and the best results have achieved by intrathecal, intravenous and intramuscular injections. Our group used a combined intrathecal and intravenous delivery method and obtained good results, which may be explained by the combination of central and peripheral actions [40].

Another issue to be discussed is the cell type that should be targeted. As described in detail above, previous studies have established that the presence of mutant SOD1 protein in glial cells can speed disease progression; however, for the development of motor neuron disease, SOD1 needs to be present in motor neurons as well $[45,47]$. Thus, 
selective SOD1 silencing in motor neurons may not be sufficient to induce sustained and significant amelioration, and other cell types, astrocytes in particular, should be targeted to attain an optimal effect.

Another important factor to consider is the optimal time window for intervention. Transgenic rodents with the SOD1G93A mutation display pathological hallmarks of the disease in the early postnatal period. Similarly, motor neurons derived from transgenic embryos show increased membrane excitability in cultures [107-111]. Furthermore, observational studies in animals have shown that clinical symptoms manifest several months after the appearance of the first pathological changes, probably due to the presence of intracellular compensatory mechanisms that later fail because of aging or traumatic/noxious injury [108]. Imaging studies in ALS patients seem to confirm the presence of early metabolic and degenerative cell-specific alterations [112]. However, the absence of specific disease biomarkers makes it extremely difficult to identify and diagnose ALS before it becomes clinically evident in the absence of a known family history or genetic hit. Thus, experimental efforts should focus on defining instrumental and biological hallmarks of early disease to allow prompt diagnosis and enrollment of patients in clinical trials. Conversely, it is still unclear whether there is a point after which silencing SOD1 is no longer effective.

\section{Experimental trials of SOD1 silencing}

Several strategies for treating ALS by silencing SOD1 have been tested at both the preclinical and clinical levels (Table 1).

\section{$\underline{5.1}$ Antisense oligonucleotides}

As discussed before, ASOs may be able to reduce the concentration of the mutant protein by binding to the target mRNA and promoting its degradation. SOD1-directed ASOs were first studied in 2006 in the SOD1-G93A transgenic mouse model, inducing a slight increase in survival (10 days, compared to the untreated group) [68]. Furthermore, our group tested morpholino-oligonucleotides (MOs) targeting SOD1 both in rodent and human fALSderived iPSCs [40]. The MOs were able to silence SOD1 expression by up to $80 \%$ both in vitro and in vivo; 
this level of silencing is one of the highest ever reported in the symptomatic stage. MOs were injected both locally and systemically and ameliorated neuromuscular function and the survival of treated mice. Moreover, MO treatment increased the number of motor neurons and axons in the spinal cord and ventral spinal roots, reduced the presence of astrogliosis and activated microglia, and caused morphological changes and reductions in GFAP, s100beta (markers of astroglia) and Iba1 (a marker of activated microglia). In addition, a reduction in the presence of misfolded SOD1 was detected by immunocytochemistry with specific antibodies. This result has important implications, as misfolding of SOD1 has also been shown to occur in sALS patients. Another group tested SOD1 ASOs in transgenic mice and rats with good results on survival and neuromuscular function [113].

Following these preclinical results, a randomized, placebo-controlled phase I trial of intrathecally injected tofersen (also called ISIS 333611, BIIB067, and IONIS SOD1Rx) was conducted in patients with SOD1 mutation, and there was a similar rate of adverse events between the two groups ( $88 \%$ in the placebo group vs. $83 \%$ in the treatment group) [69]. The most common events were postlumbar puncture syndrome, back pain, and nausea, and no doselimiting toxic effects or serious events were reported. Thus, given the good safety profile, an open-label trial aimed at evaluating the clinical response was started and is now ongoing (NCT03070119 at www.clinicaltrials.gov).

Given the invasiveness of intrathecal administration and the possibility of complications, especially in cases of repeated dosing, a calcium phosphate-lipid nanocarrier able to encapsulate ASOs was developed and tested in zebrafish. Immediately and up to 29 hours after systemic injection, ASO-carrying nanoparticles were detectable in the blood immediately and in the spinal cord [114]. Further improvements in nanoparticle-aided delivery could thus help avoid invasive intathecal administration.

\section{$\underline{5.2} \underline{\text { RNA interference: shRNAs/siRNAs }}$}

The use of hSOD1-shRNAs, siRNAs and miRNAs has proven effective in several in vivo models (Table 1). Different viral vectors, including adeno-associated viruses (AAVs), lentiviruses (LVs), rabies-glycoprotein-pseudotyped lentiviruses (RGP-LVs), and adenoviruses (AVs), have been tested. shRNAs and siRNAs provided efficient transduction and increased survival [99-101,103,115-117], and lower levels of human 
SOD1 in the spinal cord of treated animals, although only on the side ipsilateral to the injection [116], were demonstrated by indirect immunofluorescence and immunoblotting studies [103,116]. The same results were observed in the motor cortex after local intracortical injection of the construct [116]. Foust and colleagues also detected a reduction in astrogliosis, but not in microgliosis, in treated mice [103]. Nonetheless, subsequent studies detected reductions in both astrogliosis and microgliosis (using GFAP and Iba1 staining on lumbar cord sections), as well as an improvement in motor neuron survival after treatment in the presymptomatic stage [96,118]. BravoHernandez and colleagues also observed the preservation of spinal alpha-motor neurons, of interneurons and of neuromuscular junctions after subpial treatment, in comparison with sham-operated animals [96]. These results expand the potential cellular targets for SOD1 silencing from only lower motor neurons, which are often the preferred target, to other cell types as well. Interestingly, the injection of AAV9-hSOD1-shRNA into mice in the symptomatic stage (P85) resulted in greater astrocyte transduction (approx. 50\%) than neuronal transduction (approx. 8\%) [103]. In the same study, the intrathecal delivery of AAV9-shRNA to healthy nonhuman primates (Cynomolgus macaques) by lumbar puncture was able to efficiently transduce cells and reduce SOD1 at all spinal cord levels with a caudal to rostral gradient [103]. This finding is relevant as it sets the stage for human clinical trials of AAV9-mediated therapy.

As shown in Table 1, the different shRNAs and siRNAs used in previous studies were delivered at different postnatal ages (from P0 to 109), at the embryonic stage or via cross-breeding with shRNA-expressing transgenic mice $[73,119]$. The data show a certain degree of correlation between age of treatment and outcomes; in some studies, earlier silencing seemed to result in increased survival $[96,100,103,119]$. However, comparisons between different studies is hindered by the variety of delivery methods used. The reduced efficacy may have also been due also to differences in the vectors used and in the delivery method; the intramuscular and intravenous injection of AAV6 resulted in low levels of motor neuron transduction and no clinical benefit [102]. It can be hypothesized that this was the consequence of the inability of AAV6 to efficiently cross the BBB. 
These findings notwithstanding, some questions arise when considering these studies. In most of the studies, shRNAs with high silencing efficacy were used and elicited significant therapeutic benefits, but the shRNAs targeted both wild-type and mutant genes. In transgenic animals, this nonselective silencing does not interfere with the therapeutic effect, as animals expressed human mutant genes as well as endogenous genes. Therefore, the robust therapeutic effects may have been due to the high silencing efficacy of the shRNAs used. The use of an allele-specific shRNA in one experiment resulted in modest silencing, although some of the factors that contributed to this reduction in transgenic mice are not present in humans (i.e., a high number of mutant SOD1 transgene copies and higher steady state protein levels) [73]. Nevertheless, these results demonstrate that allele-specific silencing is feasible and can be further improved. To avoid a pathological decrease in the wild-type allele, Xia and colleagues developed a strategy based on the combined use of gene editing and gene replacement [120]. In their study, both mutant and wild< type genes were inhibited by shRNAs, and wild< type SOD1 was replaced by designed RNAi-resistant wild< type SODI genes through the insertion of silent mutations. This strategy resulted in the inhibition of endogenous SOD1 and replacement with the exogenous SOD1 gene in vitro. Certainly, the translation of this strategy to in vivo models would need to address potential off-target effects and toxicity concerns, but this technique could prove useful in avoiding the risk of excessive target gene silencing.

Another major obstacle in bringing RNAi therapy from the bench to the bedside is the lack of an in vivo biomarker of therapeutic response. To overcome this barrier, Iannitti and colleagues, analyzed the CSF of transgenic mice for the presence of hSOD1 protein after treatment with AAV9-shRNA and found a 63\% decrease compared to untreated controls [118]. Notably, these data suggest that CSF SOD1 protein levels could be used as a reliable biomarker to verify target engagement and correct dosing in future clinical trials in SOD1-associated ALS patients.

\section{$\underline{5.3}$ RNA interference: miRNAs}

Vectors expressing artificial miRNAs present fewer problems than their shRNA counterparts in the process of clinical translation, as they have a lower risk of toxicity, exhibit a safer immunogenic profile and produce fewer 
off-target effects [25]. Moreover, the vectors can be tailored to allow tissue-specific or conditioned expression by Pol II promoters or coexpression with fluorescent markers such as GFP or DsRed [121]. They can also be chained to sequentially transcribe multiple miRNAs from the same promoter, an approach termed combinatorial RNAi (coRNAi); this enhances silencing efficacy when the same miRNA sequence is repeated and allows the simultaneous targeting of different mRNAs by joining different miRNA sequences [121].

Taking advantage of these multiple properties, several studies have tested artificial miRNAs in SOD1 transgenic models (Table 1) [105,122-124]. Different vectors, including AAV6, AAV9 and AAVrh10, have been used and have produced promising results in terms of transduction efficiency and outcomes. For example, a single intravenous or intrathecal injection of AAVrh10 carrying hSOD1-miRNA in the symptomatic stage resulted in widespread distribution of the construct along the spinal cord in most mice and the amelioration of ALS phenotypes, delaying disease onset, extending survival and increasing the preservation of motor skills [105,122]. Notably, in the same study, AAVrh10 and AAV9 performed much better than AAV1, 2 and 8 and were able to achieve widespread transduction of motor neurons, astrocytes and oligodendrocytes along the spinal cord and into the brainstem in mouse and nonhuman primate models [122].

To evaluate the therapeutic responses of different cell types, Dirren and colleagues generated two constructs with different serotype/promoter combinations that predominantly targeted either motoneurons or astrocytes [123]. They found that following the injection of the AAV vectors into both newborn and adult mice, motor neurons were most protected when SOD1 was mainly silenced in motoneurons, with 83-92\% of motoneurons still present in end-stage mice treated at birth, while astrocyte-specific silencing led to the survival of 54-62\% of motor neurons. However, the astrocytic expression of miR SOD1 normalized motor performance and electrophysiological parameters, thus supporting a critical role of the astroglial expression of mutated SOD1 in the decline of neuromuscular function.

To further the translatability of miRNA-based techniques, Borel and colleagues delivered an AAVrh10-CB/U6/H1-miR SOD1 construct with or without GFP to healthy macaques by intrathecal catheter [70]. The constructs led to profound and reproducible SOD1 silencing and demonstrated a good safety profile, as 
measured by the abundance of the predicted mature miRNA compared to that of alternate species (a low ratio suggests a risk of potential off-target effects) and the guide/passenger strand ratio (which also limits the risk of offtarget effects). The production of neutralizing antibodies was detected after the intrathecal administration of AAVrh10, but it did not correlate with the cellular immune response and did not interfere with therapeutic efficacy. However, the cellular immune response characterized by IFN- $\gamma$-secreting $\mathrm{T}$ cells in humans cannot be precisely reproduced in animals. Excitingly, the FDA recently approved an investigational drug application (IND \#17179) for a pilot phase I clinical trial of this construct in humans, which will hopefully elucidate whether its safety profile in humans, mirrors that in animals.

\section{$\underline{5.4} \underline{\text { CRISPR/Cas } 9}$}

In recent years, CRISPR/Cas9 has gained increasing popularity as a genome editing tool due to its simplicity and relative precision. To date, CRISPR/Cas9 has been tested on fALS SOD1 iPSCs [125], but only one group attempted in vivo treatment in an SOD1 mouse model through the intravenous administration of an AAV9 vector encoding the Cas9 nuclease with an sgRNA targeting the mutant SOD1 gene [106]. This treatment yielded a reduction in the expression of mutant SOD1 protein and $\mathrm{SaCas} 9$ in the spinal cord, although this decrease was primarily limited to ChAT-expressing motor neurons. Clinically, it resulted in delayed disease onset, improved muscle function and extended survival in treated mice, although it was not able to slow ALS progression once the disease was established. The authors speculated that this may have been due to inefficient SOD1 disruption in astrocytes, which would eventually cause the abolishment of motor neuron support and give rise to secondary degeneration. Thus, optimizing Cas9 expression in different cell types (for example, by selecting a different Cas9 ortholog or creating specialized promoter sequences) appears to now be a major target for future CRISPR/Cas9 studies aimed at silencing SOD1. Another issue highlighted by this study is lack of specificity, as the sgRNA used was unable to distinguish between mutant and wild-type human SOD1 [106]. The potential risks are off-target effects and excessive SOD1 silencing. Nevertheless, future studies might develop an allele-specific CRISPR system configured to target disease-causing SOD1 mutations or a gene knockout-and-replace therapy, such as one involving shRNAs [120], to overcome these hurdles. 


\section{Conclusions}

In recent years, gene editing, and silencing strategies have managed to traverse the "valley of death" between preclinical and clinical research and have thus initiated a new era in the fields of genetic diseases. However, while the mechanism of action and endpoints might be relatively easy to establish in cases of monogenic diseases with a well-known pathological basis, such as TTR amyloidosis, or diseases with an early and rapid onset, such as SMA and DMD, navigating the sea between the bench and the bedside might prove extremely perilous in the case of a disease like ALS. Indeed, several pieces of knowledge that allow for precise definitions of therapeutic timing, delivery strategy, monitoring and endpoint are lacking for ALS; in humans, the disease often becomes evident when the neurodegeneration has already spread diffusely, and reliable, validated biomarkers of disease onset and progression are still lacking. Furthermore, although several cellular functions and pathways have been found to be disrupted, the exact relationships between neurodegeneration, neuronal loss, the impairment of glial trophic functions and neuroinflammation and their timing remain elusive. Taken together, these observations might frustrate many researchers, and we are ourselves astonished by the paucity of current clinical trials for ALS treatment worldwide considering the large number of compounds that have been tested at the preclinical level. Surely, we are missing some key pieces in the complex puzzle of ALS pathology and pathogenesis. In this regard, studying familial ALS is advantageous as we have at least a partial explanation of the initiation of the pathological process. More specifically, SOD1 represents an interesting target because it is caused by a dominant heterozygous mutation with Mendelian inheritance, and aggregates of mutant SOD1 protein have been shown to cause both motor neuron and glial degeneration in vitro and in vivo $[25,32,40,47,60]$.

Various approaches aimed at reducing the levels of mutant SOD1 protein have been tested in vivo, in most cases yielding positive results. For instance, mice treated with ASOs demonstrate a slight improvement in survival and neuromuscular function. Similarly, RNAi was studied in rodent models and was shown to have a beneficial impact on survival, especially when delivered intravenously or intrathecally in the presymptomatic or embryonic stages. In addition, shRNAs and miRNAs were found to increase neuroprotection and reduce gliosis at the histological level. Several vectors, including AAV6, AAV9 and AAVrh10, were used for their delivery. CRISPR/Cas9 was 
tested in a single mouse model and induced prolonged survival. Overall, preclinical studies highlighted the efficacy of these therapies in reducing the levels of misfolded SOD1 and increasing motor neurons survival and neuroprotection. Some of them also detected a reduction in astrogliosis and microgliosis. Results were influenced by the age of animals when treatment was administered and by the mode of delivery. As regards the former, an earlier treatment was associated with the best outcomes, while concerning the latter, intrathecal and intravenous delivery were the most successful delivery routes. However, a potential concern is the risk of off-target effects, with concomitant excessive reduction of wild-type SOD1 protein. As discussed previously, the biological effects of this depletion are not completely known, but it may provoke an increase of free radicals and consequent oxidative stress. This was not observed in animal studies, and a safety trial conducted on macaques (a model closer to human physiology) demonstrated a good safety profile, especially in terms of the absence of an immune cellular response following administration and of the off-target effect.

As regards clinical trials, Tofersen, an antisense oligonucleotide, was evaluated in a randomized, placebo-controlled phase I study in humans, and compared to sham controls, patients treated with Tofersen showed no significant adverse events. An open-label study is now ongoing to assess its efficacy in an extended time window. Moreover, after being demonstrated to be safe in nonhuman primates, an AAVrh10-CB/U6/H1-miRNA SOD1 construct recently gained investigational drug status and will soon be evaluated in a phase I clinical trial. The effective impact of these drugs on disease severity and progression remains a major question to be answered.

In preclinical studies, the key factors seem to be early administration and the selection of a delivery method that allows efficient penetration into the CNS and into the deeper layers of the spinal cord. In support of this observation, many authors have pointed out that most therapies extend the disease-free period rather than delaying progression, thus advocating for the need to identify and validate biomarkers of early disease. Nowadays, identifying ALS before it becomes clinically evident in more than one body region is extremely hard, but the timing of administration of SOD1 suppressing therapies seems to be a key factor. Future studies should concentrate on establishing which is the "point of no return", after which it is not possible to revert the disease process nor to delay neurodegeneration and clinical progression. 


\section{Expert Opinion}

SOD1 silencing techniques hold a great potential for a still incurable disease such as ALS. However, in order to bridge the gap between bench and bedside, these methods need to pass several challenges, such as demonstrating a good safety profile and a satisfactory efficacy and finding an effective and practical delivery method. To date, they have shown promising results in some preclinical models. Notwithstanding these findings, in our opinion, animal studies conducted to date have several limitations. First, the most widely used model is a high-copy SOD1-G93A transgenic mouse; the therapeutic effects observed in this line likely result from the high silencing efficacy of the constructs used, which often have low allele specificity. It is still unclear whether a lower efficacy would still result in a widespread effect and a clinical benefit when translated to humans. Furthermore, it has long been believed that while SOD1 misfolding and accumulation are responsible for ALS, SOD1 depletion is not associated with any known pathological effect. However, a recent report of a patient with inherited SOD1 deficiency challenged this belief [67]. Functional assays demonstrated a reduction in SOD1 activity in this patient. This discovery makes allele specificity a primary goal in the development of human silencing techniques. Another potential approach for avoiding a toxic reduction in the expression of the target gene is the combination of gene silencing and gene replacement, an innovative technique that has proven efficacious in a mouse model of ALS [120]. This approach is currently being used in other neurological diseases as well; for example, our group is currently studying a combined approach involving the codelivery of an shRNA with an engineered RNAi-resistant gene for the treatment of congenital MFN2-related Charcot-Marie-Tooth (data under publication). This strategy is, in our opinion, extremely promising for counteracting the risk of wild-type allele silencing. Another challenge that has to be overcome, before these drugs may enter the general market, is finding a safe but also economically sustainable method of production, in order to allow a high number of patients to access them.

Nevertheless, despite the hurdles that we have exposed, the first steps in moving some of the illustrated approaches to the clinic have been achieved. Given their simplicity and their ability to be directly administered to the CNS without the concerns associated with viral vectors, ASOs will likely soon progress to the next stages of clinical research and possibly reach the general market. Some interesting nanoengineering strategies aimed at improving 
the delivery process and avoiding repeated invasive lumbar punctures are currently being studied [114]. However, in our opinion, the short half-life of these compounds makes RNAi and CRISPR-based approaches more appealing, give their potential to induce sustained construct expression. Thus, it is essential to further evaluate delivery methods and safety. Considering that as a whole ALS is complicated, as opposed to monogenic diseases, the ideal SOD1 silencing reagent would probably have the ability to cross the BBB and to act on different areas of the CNS and on different cell types. RNA-interference techniques combined with AAVs are probably the closest to this goal, as they proved able to transfect different cell types after injection (both intravenous and intrathecal) at different clinical stages in preclinical studies. One compound is also entering clinical trials right now (IND\#17179). However, several issues needs to be addressed, such as safety in humans and efficacy after the disease is clinically established. To this regard, future research will need to focus on the development of biomarkers of early disease to protect against motor neuron degeneration in a timely manner. Many studies have demonstrated that most SOD1-silencing therapies prolong the disease-free period rather than delaying progression. Furthermore, as we discussed above there seems to be a correlation between time of intervention and outcome in animal models. In our opinion, treating patients once the disease is clinically established might not revert the pathogenic process, even if a reduction in SOD1 levels is achieved. Thus, acting early seems to be essential for therapeutic success.

Overall, we believe that silencing strategies represent the most exciting and promising approaches for SOD1-related ALS and may succeed where all other drugs have failed thus far, provided that researchers will be able to find answers to these unsolved questions that still burden ALS research. Other innovative therapeutic strategies have been studied against ALS, however they are unlikely to be ready for bedside use in the following years; for instance, stem cell transplantation [126]. Considering other approaches, no pharmaceutical compound proved able to prolong survival by more than some months $[3,127]$. Given these points, and the tremendous progresses made by gene silencing and editing research in the past years, we believe that the techniques discussed in this review might advance faster than others in the foreseeable future. Hopefully, in the next five years we might withstand SOD1-targeting ASOs passing clinical trials and entering general market, provided that the correct ALS population to target is identified; in addition to that, RNAi-based therapies might also enter the clinical trial phase. 
Nowadays, increasing interest is being given by the scientific community to the development of CRISPR/Cas9 technology, so we hypothesize that CRISPR-based studied might catalyze efforts and funding and thus establish a solid preclinical ground and be ready for clinical phase by five or, maybe, ten years. We also think that genomic studies might soon identify other potential genetic targets which influence disease development in sporadic ALS, such as genes involved in neuroinflammation and protection from oxidative injury, allowing for the application of gene modulation also in these patients. We find unrealistic that in ten years a definitive treatment for sporadic ALS will be available, but it is reasonable to believe that some disease-modifying agents will be ready for genetic forms, such as SOD1-related ALS. SOD1 silencing techniques might help us to reach this goal.

\section{Acknowledgments}

We thank the Associazione Amici del Centro Dino Ferrari for its support. Figure was modified from images from Servier Medical Art, licensed under a Creative Common Attribution 3.0 Generic License. http://smart.servier.com/

\section{Funding}

This paper was not funded.

\section{Declaration of interest}

The authors have no relevant affiliations or financial involvement with any organization or entity with a financial interest in or financial conflict with the subject matter or materials discussed in the manuscript. This includes employment, consultancies, honoraria, stock ownership or options, expert testimony, grants or patents received or pending, or royalties.

\section{$\underline{\text { Reviewer disclosures }}$}

Peer reviewers on this manuscript have no relevant financial or other relationships to disclose

\section{References}

Papers of special note have been highlighted as either of interest $(\bullet)$ or of considerable interest $(\bullet \bullet)$ to readers 
[1] Hardiman O, Al-Chalabi A, Chio A, et al. Amyotrophic lateral sclerosis. Nat. Publ. Gr. [Internet]. 2017 [cited 2018 Mar 30];3. Available from: https://www.nature.com/articles/nrdp201785.pdf.

[2] Chiò A, Logroscino G, Traynor BJ, et al. Global epidemiology of amyotrophic lateral sclerosis: a systematic review of the published literature. Neuroepidemiology [Internet]. 2013 [cited $2018 \mathrm{Apr}$ 2];41:118-130. Available from: http://www.ncbi.nlm.nih.gov/pubmed/23860588.

[3] Nowicka N, Juranek J, Juranek JK, et al. Risk Factors and Emerging Therapies in Amyotrophic Lateral Sclerosis. Int. J. Mol. Sci. [Internet]. 2019 [cited 2019 Sep 5];20. Available from: http://www.ncbi.nlm.nih.gov/pubmed/31141951.

[4] Rosen D. Mutations in $\mathrm{Cu} / \mathrm{Zn}$ superoxide dismutase gene are associated with familial amyotrophic lateral sclerosis. Nature [Internet]. 1993 [cited 2019 Sep 5];364:362-362. Available from: http://www.ncbi.nlm.nih.gov/pubmed/8332197.

[5] Abel O, Powell JF, Andersen PM, et al. ALSoD: A user-friendly online bioinformatics tool for amyotrophic lateral sclerosis genetics. Hum. Mutat. [Internet]. 2012 [cited 2019 Nov 22];33:1345-1351. Available from: http://doi.wiley.com/10.1002/humu.22157.

[6] ALS Knowledge Portal.

[7] Farhan SMK, Howrigan DP, Abbott LE, et al. Enrichment of rare protein truncating variants in amyotrophic lateral sclerosis patients. bioRxiv [Internet]. 2018 [cited 2020 Jan 27];307835. Available from: https://www.biorxiv.org/content/10.1101/307835v2.

[8] van der Spek RAA, van Rheenen W, Pulit SL, et al. The project MinE databrowser: bringing large-scale whole-genome sequencing in ALS to researchers and the public. Amyotroph. Lateral Scler. Frontotemporal Degener. [Internet]. 2019 [cited 2020 Jan 27];20:432-440. Available from: http://www.ncbi.nlm.nih.gov/pubmed/31280677.

[9] Andersen PM, Nilsson P, Forsgren L, et al. CuZn-superoxide dismutase, extracellular superoxide dismutase, and glutathione peroxidase in blood from individuals homozygous for Asp90Ala CuZu-superoxide dismutase mutation. J. Neurochem. [Internet]. 1998 [cited 2019 Nov 27];70:715-720. Available from: http://www.ncbi.nlm.nih.gov/pubmed/9453566.

[10] Andersen PM, Forsgren L, Binzer M, et al. Autosomal recessive adult-onset amyotrophic lateral sclerosis associated with homozygosity for Asp90Ala CuZn-superoxide dismutase mutation. A clinical and genealogical study of 36 patients. Brain [Internet]. 1996 [cited 2019 Nov 27];119 ( Pt 4):1153-1172. Available from: http://www.ncbi.nlm.nih.gov/pubmed/8813280.

[11] McCord JM, Fridovich I. Superoxide dismutase. An enzymic function for erythrocuprein (hemocuprein). J. Biol. Chem. [Internet]. 1969 [cited 2019 Sep 5];244:6049-6055. Available from: http://www.ncbi.nlm.nih.gov/pubmed/5389100.

[12] Hörnberg A, Logan DT, Marklund SL, et al. The coupling between disulphide status, metallation and dimer interface strength in $\mathrm{Cu} / \mathrm{Zn}$ superoxide dismutase. J. Mol. Biol. [Internet]. 2007 [cited 2020 Jan 21];365:333-342. Available from: http://www.ncbi.nlm.nih.gov/pubmed/17070542.

[13] Arnesano F, Banci L, Bertini I, et al. The unusually stable quaternary structure of human $\mathrm{Cu}, \mathrm{Zn}$-superoxide dismutase 1 is controlled by both metal occupancy and disulfide status. J. Biol. Chem. [Internet]. 2004 [cited 2020 Jan 21];279:47998-48003. Available from: https://pubmed.ncbi.nlm.nih.gov/15326189-the-unusually-stable-quaternary-structure-of-humancuzn-superoxide-dismutase-1-is-controlled-by-both-metal-occupancy-and-disulfide-status/?from _single_result=he+unusually+stable+quaternary+structure+of+human+Cu\%2CZ.

[14] Banci L, Bertini I, Cantini F, et al. Human superoxide dismutase 1 (hSOD1) maturation through interaction with human copper chaperone for SOD1 (hCCS). Proc. Natl. Acad. Sci. U. S. A. [Internet]. 2012 [cited 2020 Jan 21];109:13555-13560. Available from: http://www.ncbi.nlm.nih.gov/pubmed/22869735.

[15] Carroll MC, Girouard JB, Ulloa JL, et al. Mechanisms for activating $\mathrm{Cu}$ - and $\mathrm{Zn}$-containing 
superoxide dismutase in the absence of the CCS Cu chaperone. Proc. Natl. Acad. Sci. U. S. A. [Internet]. 2004 [cited 2020 Jan 21];101:5964-5969. Available from:

http://www.ncbi.nlm.nih.gov/pubmed/15069187.

[16] Brown NM, Torres AS, Doan PE, et al. Oxygen and the copper chaperone CCS regulate posttranslational activation of $\mathrm{Cu}, \mathrm{Zn}$ superoxide dismutase. Proc. Natl. Acad. Sci. U. S. A. [Internet]. 2004 [cited 2020 Jan 21];101:5518-5523. Available from: http://www.ncbi.nlm.nih.gov/pubmed/15064408.

[17] Fetherolf M, Boyd SD, Winkler DD, et al. Oxygen-dependent activation of Cu,Zn-superoxide dismutase-1. Metallomics [Internet]. 2017;9:1047-1059. Available from: http://dx.doi.org/10.1039/C6MT00298F. *An authoritative review of the mechanisms of SOD1 activation, with a focus on copper ion insertion and disulfide bond formation.

[18] Quinlan CL, Goncalves RLS, Hey-Mogensen M, et al. The 2-oxoacid dehydrogenase complexes in mitochondria can produce superoxide/hydrogen peroxide at much higher rates than complex I [Internet]. J. Biol. Chem. J Biol Chem; 2014 [cited 2020 Jan 21]. p. 8312-8325. Available from: https://pubmed.ncbi.nlm.nih.gov/24515115-the-2-oxoacid-dehydrogenase-complexes-in-mitocho ndria-can-produce-superoxidehydrogen-peroxide-at-much-higher-rates-than-complex-i/?from_si ngle_result=The+2-oxoacid+dehydrogenase+complexes+in+mitochondria+can+produc.

[19] Field LS, Furukawa Y, O'Halloran T V, et al. Factors controlling the uptake of yeast copper/zinc superoxide dismutase into mitochondria. J. Biol. Chem. [Internet]. 2003 [cited 2020 Jan 21];278:28052-28059. Available from: http://www.ncbi.nlm.nih.gov/pubmed/12748182.

[20] Kawamata H, Manfredi G. Different regulation of wild-type and mutant $\mathrm{Cu}, \mathrm{Zn}$ superoxide dismutase localization in mammalian mitochondria. Hum. Mol. Genet. [Internet]. 2008 [cited 2020 Jan 21];17:3303-3317. Available from: http://www.ncbi.nlm.nih.gov/pubmed/18703498.

[21] Foreman J, Demidchik V, Bothwell JHF, et al. Reactive oxygen species produced by NADPH oxidase regulate plant cell growth. Nature [Internet]. 2003 [cited 2020 Jan 21];422:442-446. Available from: http://www.ncbi.nlm.nih.gov/pubmed/12660786.

[22] Cleveland DW, Laing N, Hurse P V., et al. Toxic mutants in Charcot's sclerosis. Nature [Internet]. 1995 [cited 2019 Nov 22];378:342-343. Available from: http://www.nature.com/articles/378342a0.

[23] Gurney $\mathrm{M}, \mathrm{Pu} \mathrm{H}$, Chiu A, et al. Motor neuron degeneration in mice that express a human $\mathrm{Cu}, \mathrm{Zn}$ superoxide dismutase mutation. science.sciencemag.org [Internet]. [cited 2019 Nov 22]; Available from: https://science.sciencemag.org/content/264/5166/1772.short.

[24] Reaume A, Elliott J, Hoffman E, et al. Motor neurons in $\mathrm{Cu} / \mathrm{Zn}$ superoxide dismutase-deficient mice develop normally but exhibit enhanced cell death after axonal injury. nature.com [Internet]. [cited 2019 Nov 22]; Available from: https://www.nature.com/articles/ng0596-43.

[25] van Zundert B, Brown RH. Silencing strategies for therapy of SOD1-mediated ALS. Neurosci. Lett. [Internet]. 2017;636:32-39. Available from: http://dx.doi.org/10.1016/j.neulet.2016.07.059.

[26] Guareschi S, Cova E, Cereda C, et al. An over-oxidized form of superoxide dismutase found in sporadic amyotrophic lateral sclerosis with bulbar onset shares a toxic mechanism with mutant SOD1. Proc. Natl. Acad. Sci. U. S. A. [Internet]. 2012 [cited 2019 Nov 26];109:5074. Available from: https://www.ncbi.nlm.nih.gov/pmc/articles/PMC3324021/.

[27] Ezzi SA, Urushitani M, Julien J-P. Wild-type superoxide dismutase acquires binding and toxic properties of ALS-linked mutant forms through oxidation. J. Neurochem. [Internet]. 2007 [cited 2019 Nov 26];102:170-178. Available from: http://www.ncbi.nlm.nih.gov/pubmed/17394546.

[28] Bosco DA, Morfini G, Karabacak NM, et al. Wild-type and mutant SOD1 share an aberrant conformation and a common pathogenic pathway in ALS. Nat. Neurosci. [Internet]. 2010 [cited 2019 Nov 26];13:1396. Available from: https://www.ncbi.nlm.nih.gov/pmc/articles/PMC2967729/. 
[29] Liu J, Lillo C, Jonsson PA, et al. Toxicity of familial ALS-linked SOD1 mutants from selective recruitment to spinal mitochondria. Neuron [Internet]. 2004 [cited 2020 Jan 21];43:5-17. Available from: http://www.ncbi.nlm.nih.gov/pubmed/15233913.

[30] Cozzolino M, Pesaresi MG, Amori I, et al. Oligomerization of mutant SOD1 in mitochondria of motoneuronal cells drives mitochondrial damage and cell toxicity. Antioxid. Redox Signal. [Internet]. 2009 [cited 2020 Jan 21];11:1547-1558. Available from: http://www.ncbi.nlm.nih.gov/pubmed/19344252.

[31] Kaur SJ, McKeown SR, Rashid S. Mutant SOD1 mediated pathogenesis of Amyotrophic Lateral Sclerosis [Internet]. Gene. Gene; 2016 [cited 2020 Jan 23]. p. 109-118. Available from: http://www.ncbi.nlm.nih.gov/pubmed/26657039.

[32] Hayashi Y, Homma K, Ichijo H. SOD1 in neurotoxicity and its controversial roles in SOD1 mutation-negative ALS. Adv. Biol. Regul. [Internet]. 2016 [cited 2019 Dec 12];60:95-104. Available from: http://www.ncbi.nlm.nih.gov/pubmed/26563614.

[33] Nishitoh H, Kadowaki H, Nagai A, et al. ALS-linked mutant SOD1 induces ER stress- and ASK1-dependent motor neuron death by targeting Derlin-1. Genes Dev. [Internet]. 2008 [cited 2020 Jan 22];22:1451-1464. Available from: http://www.ncbi.nlm.nih.gov/pubmed/18519638.

[34] Doyle KM, Kennedy D, Gorman AM, et al. Unfolded proteins and endoplasmic reticulum stress in neurodegenerative disorders. J. Cell. Mol. Med. [Internet]. 2011 [cited 2020 Jan 22];15:20252039. Available from: http://www.ncbi.nlm.nih.gov/pubmed/21722302.

[35] Fujisawa T, Homma K, Yamaguchi N, et al. A novel monoclonal antibody reveals a conformational alteration shared by amyotrophic lateral sclerosis-linked SOD1 mutants. Ann. Neurol. [Internet]. 2012 [cited 2019 Nov 22];72:739-749. Available from: http://doi.wiley.com/10.1002/ana.23668.

[36] Münch C, biology AB-J of molecular, 2010 undefined. Exposure of hydrophobic surfaces initiates aggregation of diverse ALS-causing superoxide dismutase-1 mutants. Elsevier [Internet]. [cited 2019 Nov 22]; Available from: https://www.sciencedirect.com/science/article/pii/S0022283610003803.

[37] Atkin J, Farg M, Turner B, et al. Induction of the unfolded protein response in familial amyotrophic lateral sclerosis and association of protein-disulfide isomerase with superoxide dismutase 1. ASBMB [Internet]. [cited 2019 Nov 26]; Available from: http://www.jbc.org/content/281/40/30152.short.

[38] Chen X, Zhang X, Li C, et al. S-nitrosylated protein disulfide isomerase contributes to mutant SOD1 aggregates in amyotrophic lateral sclerosis. J. Neurochem. [Internet]. 2013 [cited 2019 Nov 26];124:45-58. Available from: http://doi.wiley.com/10.1111/jnc.12046.

[39] Israelson A, Ditsworth D, Sun S, et al. Macrophage migration inhibitory factor as a chaperone inhibiting accumulation of misfolded SOD1. Elsevier [Internet]. [cited 2019 Nov 26]; Available from: https://www.sciencedirect.com/science/article/pii/S089662731500149X.

[40] Nizzardo M, Simone C, Rizzo F, et al. Morpholino-mediated SOD1 reduction ameliorates an amyotrophic lateral sclerosis disease phenotype. Sci. Rep. [Internet]. 2016 [cited 2019 Sep 4];6:21301. Available from: http://www.ncbi.nlm.nih.gov/pubmed/26878886.

[41] Rotunno MS, Bosco DA. An emerging role for misfolded wild-type SOD1 in sporadic ALS pathogenesis. Front. Cell. Neurosci. [Internet]. 2013 [cited 2019 Nov 26];7:253. Available from: http://www.ncbi.nlm.nih.gov/pubmed/24379756.

[42] Forsberg K, Jonsson PA, Andersen PM, et al. Novel antibodies reveal inclusions containing non-native SOD1 in sporadic ALS patients. PLoS One [Internet]. 2010 [cited 2019 Nov 26];5:e11552. Available from: http://www.ncbi.nlm.nih.gov/pubmed/20644736.

[43] Haidet-Phillips AM, Hester ME, Miranda CJ, et al. Astrocytes from familial and sporadic ALS patients are toxic to motor neurons. Nat. Biotechnol. [Internet]. 2011 [cited 2018 Dec 18];29:824- 
828. Available from: http://www.nature.com/articles/nbt.1957.

[44] Yamanaka K, Chun SJ, Boillee S, et al. Astrocytes as determinants of disease progression in inherited amyotrophic lateral sclerosis. Nat. Neurosci. [Internet]. 2008 [cited 2018 Apr 16];11:251-253. Available from: http://www.nature.com/articles/nn2047.

[45] Boillée S, Yamanaka K, Lobsiger CS, et al. Onset and progression in inherited ALS determined by motor neurons and microglia. Science (80-. ). [Internet]. 2006 [cited 2019 Nov 27];312:13891392. Available from:

https://pubmed.ncbi.nlm.nih.gov/16741123-onset-and-progression-in-inherited-als-determined-b y-motor-neurons-and-microglia/.

[46] Kang SH, Li Y, Fukaya M, et al. Degeneration and impaired regeneration of gray matter oligodendrocytes in amyotrophic lateral sclerosis. Nat. Neurosci. [Internet]. 2013 [cited 2019 Nov 27];16:571-579. Available from: http://www.ncbi.nlm.nih.gov/pubmed/23542689.

[47] Ilieva H, Polymenidou M, Cleveland DW. Non-cell autonomous toxicity in neurodegenerative disorders: ALS and beyond [Internet]. J. Cell Biol. 2009 [cited 2019 Dec 2]. p. 761-772. Available from: http://jcb.rupress.org/content/187/6/761.short.

[48] Di Giorgio FP, Carrasco MA, Siao MC, et al. Non-cell autonomous effect of glia on motor neurons in an embryonic stem cell-based ALS model. Nat. Neurosci. [Internet]. 2007 [cited 2019 Dec 2];10:608-614. Available from: http://www.nature.com/articles/nn1885.

[49] Nagai M, Re DB, Nagata T, et al. Astrocytes expressing ALS-linked mutated SOD1 release factors selectively toxic to motor neurons. Nat. Neurosci. [Internet]. 2007 [cited $2019 \mathrm{Dec}$ 2];10:615-622. Available from: http://www.ncbi.nlm.nih.gov/pubmed/17435755.

[50] Fritz E, Izaurieta P, Weiss A, et al. Mutant SOD1-expressing astrocytes release toxic factors that trigger motoneuron death by inducing hyperexcitability. J. Neurophysiol. [Internet]. 2013 [cited 2019 Dec 2];109:2803-2814. Available from: https://www.physiology.org/doi/10.1152/jn.00500.2012.

[51] Rojas F, Cortes N, Abarzua S, et al. Astrocytes expressing mutant SOD1 and TDP43 trigger motoneuron death that is mediated via sodium channels and nitroxidative stress. Front. Cell. Neurosci. [Internet]. 2014 [cited 2019 Dec 2];8:24. Available from: http://journal.frontiersin.org/article/10.3389/fncel.2014.00024/abstract.

[52] Rojas F, Gonzalez D, Cortes N, et al. Reactive oxygen species trigger motoneuron death in non-cell-autonomous models of ALS through activation of c-Abl signaling. Front. Cell. Neurosci. [Internet]. 2015 [cited 2019 Dec 2];09:203. Available from: http://journal.frontiersin.org/Article/10.3389/fncel.2015.00203/abstract.

[53] Marchetto MCN, Muotri AR, Mu Y, et al. Non-Cell-Autonomous Effect of Human SOD1G37R Astrocytes on Motor Neurons Derived from Human Embryonic Stem Cells. Cell Stem Cell [Internet]. 2008 [cited 2019 Dec 2];3:649-657. Available from: https://www.sciencedirect.com/science/article/pii/S1934590908005249.

[54] Meyer K, Ferraiuolo L, Miranda CJ, et al. Direct conversion of patient fibroblasts demonstrates non-cell autonomous toxicity of astrocytes to motor neurons in familial and sporadic ALS. Proc. Natl. Acad. Sci. U. S. A. [Internet]. 2014 [cited 2019 Dec 2];111:829-832. Available from: http://www.ncbi.nlm.nih.gov/pubmed/24379375.

[55] Re DB, Le Verche V, Yu C, et al. Necroptosis Drives Motor Neuron Death in Models of Both Sporadic and Familial ALS. Neuron [Internet]. 2014 [cited 2019 Dec 2];81:1001-1008. Available from: https://www.sciencedirect.com/science/article/pii/S0896627314000166.

[56] Papadeas S, Kraig S, ... CO-P of the, et al. Astrocytes carrying the superoxide dismutase 1 (SOD1G93A) mutation induce wild-type motor neuron degeneration in vivo. Natl. Acad Sci. [Internet]. [cited 2019 Dec 2]; Available from: https://www.pnas.org/content/108/43/17803.short.

[57] Grad LI, Yerbury JJ, Turner BJ, et al. Intercellular propagated misfolding of wild-type Cu/Zn 
superoxide dismutase occurs via exosome-dependent and -independent mechanisms. Proc. Natl. Acad. Sci. U. S. A. [Internet]. 2014 [cited 2019 Nov 27];111:3620-3625. Available from: https://www.pnas.org/content/111/9/3620.short.

[58] Urushitani M, Sik A, Sakurai T, et al. Chromogranin-mediated secretion of mutant superoxide dismutase proteins linked to amyotrophic lateral sclerosis. nature.com [Internet]. [cited 2019 Nov 27]; Available from: https://www.nature.com/articles/nn1603.

[59] Sundaramoorthy V, Walker AK, Yerbury J, et al. Extracellular wildtype and mutant SOD1 induces ER-Golgi pathology characteristic of amyotrophic lateral sclerosis in neuronal cells. Cell. Mol. Life Sci. [Internet]. 2013 [cited 2019 Nov 27];70:4181-4195. Available from: http://link.springer.com/10.1007/s00018-013-1385-2.

[60] Bidhendi EE, Bergh J, Zetterström P, et al. Two superoxide dismutase prion strains transmit amyotrophic lateral sclerosis-like disease. J. Clin. Invest. [Internet]. 2016 [cited 2019 Nov 27];126:2249-2253. Available from: https://www.jci.org/articles/view/84360.

[61] Ayers JI, Fromholt S, Koch M, et al. Experimental transmissibility of mutant SOD1 motor neuron disease. Acta Neuropathol. [Internet]. 2014 [cited 2019 Nov 27];128:791-803. Available from: http://link.springer.com/10.1007/s00401-014-1342-7.

[62] Deng H, Hentati A, Tainer J, et al. Amyotrophic lateral sclerosis and structural defects in $\mathrm{Cu}, \mathrm{Zn}$ superoxide dismutase. Science (80-. ). [Internet]. 1993 [cited 2019 Nov 27];261:1047-1051. Available from: http://www.ncbi.nlm.nih.gov/pubmed/8351519.

[63] Rosen DR, Siddique T, Patterson D, et al. Mutations in Cu/Zn superoxide dismutase gene are associated with familial amyotrophic lateral sclerosis. Nature [Internet]. 1993 [cited 2019 Nov 27];362:59-62. Available from: http://www.nature.com/articles/362059a0.

[64] Reaume AG, Elliott JL, Hoffman EK, et al. Motor neurons in Cu/Zn superoxide dismutase-deficient mice develop normally but exhibit enhanced cell death after axonal injury. Nat. Genet. [Internet]. 1996 [cited 2019 Nov 27];13:43-47. Available from: http://www.nature.com/articles/ng0596-43.

[65] Fischer LR, Li Y, Asress SA, et al. Absence of SOD1 leads to oxidative stress in peripheral nerve and causes a progressive distal motor axonopathy. Exp. Neurol. [Internet]. 2012 [cited 2019 Dec 12];233:163-171. Available from: http://www.ncbi.nlm.nih.gov/pubmed/21963651.

[66] Muller FL, Song W, Liu Y, et al. Absence of CuZn superoxide dismutase leads to elevated oxidative stress and acceleration of age-dependent skeletal muscle atrophy. Free Radic. Biol. Med. [Internet]. 2006 [cited 2019 Dec 12];40:1993-2004. Available from: http://www.ncbi.nlm.nih.gov/pubmed/16716900.

[67] Park JH, Elpers C, Reunert J, et al. SOD1 deficiency: a novel syndrome distinct from amyotrophic lateral sclerosis. Brain [Internet]. 2019 [cited 2019 Nov 27];142:2230-2237. Available from: https://academic.oup.com/brain/article/142/8/2230/5536868. **The first report of an inherited SOD1-deficiency syndrome, characterized by ataxia, hyperekplexia and developmental delay.

[68] Smith RA, Miller TM, Yamanaka K, et al. Antisense oligonucleotide therapy for neurodegenerative disease. J. Clin. Invest. [Internet]. 2006 [cited 2019 Dec 6];116:2290-2296. Available from: http://www.ncbi.nlm.nih.gov/pubmed/16878173.

[69] Miller TM, Pestronk A, David W, et al. An antisense oligonucleotide against SOD1 delivered intrathecally for patients with SOD1 familial amyotrophic lateral sclerosis: A phase 1, randomised, first-in-man study. Lancet Neurol. [Internet]. 2013 [cited 2019 Dec 6];12:435-442. Available from: https://www.sciencedirect.com/science/article/pii/S1474442213700619. **This study describes the first clinical trial of SOD1 silencing in humans: a phase 1, randomized trial using antisense oligonucleotides.

[70] Borel F, Gernoux G, Sun H, et al. Safe and effective superoxide dismutase 1 silencing using artificial microRNA in macaques. Sci. Transl. Med. [Internet]. 2018 [cited 2019 Dec 11];10. 
Available from: http://www.ncbi.nlm.nih.gov/pubmed/30381409.

[71] Iuchi Y, Okada F, Onuma K, et al. Elevated oxidative stress in erythrocytes due to a SOD1 deficiency causes anaemia and triggers autoantibody production. Biochem. J. [Internet]. 2007 [cited 2020 Jan 24];402:219-227. Available from: http://www.ncbi.nlm.nih.gov/pubmed/17059387.

[72] Anderson CM, Sonis ST, Lee CM, et al. Phase 1b/2a Trial of the Superoxide Dismutase Mimetic GC4419 to Reduce Chemoradiotherapy-Induced Oral Mucositis in Patients With Oral Cavity or Oropharyngeal Carcinoma. Int. J. Radiat. Oncol. Biol. Phys. [Internet]. 2018 [cited 2020 Jan 24];100:427-435. Available from: http://www.ncbi.nlm.nih.gov/pubmed/29174131.

[73] Xia X, Zhou H, Huang Y, et al. Allele-specific RNAi selectively silences mutant SOD1 and achieves significant therapeutic benefit in vivo. Neurobiol. Dis. [Internet]. 2006 [cited 2019 Apr 10];23:578-586. Available from: https://linkinghub.elsevier.com/retrieve/pii/S0969996106001021.

[74] Rinaldi C, Wood MJA. Antisense oligonucleotides: the next frontier for treatment of neurological disorders. Nat. Rev. Neurol. [Internet]. 2018 [cited 2019 Dec 3];14:9-21. Available from: http://www.ncbi.nlm.nih.gov/pubmed/29192260.

[75] Herrmann DN. Experimental therapeutics in hereditary neuropathies: the past, the present, and the future. Neurotherapeutics [Internet]. 2008 [cited 2019 Dec 3];5:507-515. Available from: http://www.ncbi.nlm.nih.gov/pubmed/19019301.

[76] Voelker R. First DMD Drug Gains Approval. JAMA [Internet]. 2016 [cited 2019 Dec 3];316:1756. Available from: http://www.ncbi.nlm.nih.gov/pubmed/27802526.

[77] Finkel RS, Mercuri E, Darras BT, et al. Nusinersen versus Sham Control in Infantile-Onset Spinal Muscular Atrophy. N. Engl. J. Med. [Internet]. 2017 [cited 2018 Jan 25];377:1723-1732. Available from: http://www.nejm.org/doi/10.1056/NEJMoa1702752.

[78] Deng Y, Wang CC, Choy KW, et al. Therapeutic potentials of gene silencing by RNA interference: principles, challenges, and new strategies. Gene [Internet]. 2014 [cited 2019 Dec 4];538:217-227. Available from: http://www.ncbi.nlm.nih.gov/pubmed/24406620.

[79] Hoy SM. Patisiran: First Global Approval. Drugs [Internet]. 2018 [cited 2019 Dec 4];78:16251631. Available from: http://www.ncbi.nlm.nih.gov/pubmed/30251172.

[80] Adams D, Gonzalez-Duarte A, O'Riordan WD, et al. Patisiran, an RNAi therapeutic, for hereditary transthyretin amyloidosis. N. Engl. J. Med. [Internet]. 2018 [cited 2019 Dec 4];379:1121. Available from:

https://pubmed.ncbi.nlm.nih.gov/29972753-patisiran-an-rnai-therapeutic-for-hereditary-transthyr etin-amyloidosis/?from_term=patisiran\&from_pos=2.

[81] Stessl M, Marchetti-Deschmann M, Winkler J, et al. A proteomic study reveals unspecific apoptosis induction and reduction of glycolytic enzymes by the phosphorothioate antisense oligonucleotide oblimersen in human melanoma cells. J. Proteomics [Internet]. 2009 [cited 2020 Jan 27];72:1019-1030. Available from: https://www.sciencedirect.com/science/article/pii/S1874391909001687.

[82] Hall AHS, Wan J, Shaughnessy EE, et al. RNA interference using boranophosphate siRNAs: Structure-activity relationships. Nucleic Acids Res. [Internet]. 2004 [cited 2020 Jan 27];32:59916000. Available from: https://academic.oup.com/nar/article-lookup/doi/10.1093/nar/gkh936.

[83] Allen TM. Ligand-targeted therapeutics in anticancer therapy [Internet]. Nat. Rev. Cancer. Nature Publishing Group; 2002 [cited 2020 Jan 27]. p. 750-763. Available from:

http://www.nature.com/articles/nrc903.

[84] Kruminis-Kaszkiel E, Juranek J, Maksymowicz W, et al. CRISPR/Cas9 Technology as an Emerging Tool for Targeting Amyotrophic Lateral Sclerosis (ALS). Int. J. Mol. Sci. [Internet]. 2018 [cited 2019 Dec 4];19. Available from: 
https://www.ncbi.nlm.nih.gov/pmc/articles/PMC5877767/.

[85] Zhang X-H, Tee LY, Wang X-G, et al. Off-target Effects in CRISPR/Cas9-mediated Genome Engineering. Mol. Ther. Nucleic Acids [Internet]. 2015 [cited 2019 Dec 5];4:e264. Available from: http://www.ncbi.nlm.nih.gov/pubmed/26575098.

[86] Gao Q, Dong X, Xu Q, et al. Therapeutic potential of CRISPR/Cas9 gene editing in engineered $\mathrm{T}<$ cell therapy. Cancer Med. [Internet]. 2019 [cited 2019 Dec 5];8:cam4.2257. Available from: http://www.ncbi.nlm.nih.gov/pubmed/31199589.

[87] Barbullushi K, Abati E, Rizzo F, et al. Disease Modeling and Therapeutic Strategies in CMT2A: State of the Art. Mol. Neurobiol. [Internet]. 2019 [cited 2019 Dec 6];56:6460-6471. Available from: http://www.ncbi.nlm.nih.gov/pubmed/30830587.

[88] DeVos SL, Miller TM. Direct intraventricular delivery of drugs to the rodent central nervous system. J. Vis. Exp. [Internet]. 2013 [cited 2019 Dec 6];e50326. Available from: http://www.ncbi.nlm.nih.gov/pubmed/23712122.

[89] Weinberg MS, Samulski RJ, McCown TJ. Adeno-associated virus (AAV) gene therapy for neurological disease. Neuropharmacology [Internet]. 2013 [cited 2019 Dec 6];69:82-88. Available from: https://www.sciencedirect.com/science/article/pii/S0028390812000883?via\%3Dihub.

[90] Markakis EA, Vives KP, Bober J, et al. Comparative Transduction Efficiency of AAV Vector Serotypes 1-6 in the Substantia Nigra and Striatum of the Primate Brain. Mol. Ther. [Internet]. 2010 [cited 2019 Dec 6];18:588-593. Available from: https://www.sciencedirect.com/science/article/pii/S1525001616323085?via\%3Dihub.

[91] Hadaczek P, Forsayeth J, Mirek H, et al. Transduction of nonhuman primate brain with adenoassociated virus serotype 1: vector trafficking and immune response. Hum. Gene Ther. [Internet]. 2009 [cited 2019 Dec 6];20:225-237. Available from: http://www.ncbi.nlm.nih.gov/pubmed/19292604.

[92] Foust KD, Nurre E, Montgomery CL, et al. Intravascular AAV9 preferentially targets neonatal neurons and adult astrocytes. Nat. Biotechnol. [Internet]. 2009 [cited 2019 Apr 10];27:59-65. Available from: http://www.ncbi.nlm.nih.gov/pubmed/19098898.

[93] Meyer K, Ferraiuolo L, Schmelzer L, et al. Improving Single Injection CSF Delivery of AAV9-mediated Gene Therapy for SMA: A Dose-response Study in Mice and Nonhuman Primates. Mol. Ther. [Internet]. 2015 [cited 2019 Apr 10];23:477-487. Available from: http://www.ncbi.nlm.nih.gov/pubmed/25358252.

[94] Foust KD, Salazar DL, Likhite S, et al. Therapeutic AAV9-mediated Suppression of Mutant SOD1 Slows Disease Progression and Extends Survival in Models of Inherited ALS. Mol. Ther. [Internet]. 2013 [cited 2019 Dec 6];21:2148-2159. Available from: https://www.sciencedirect.com/science/article/pii/S1525001616309418?via\%3Dihub.

[95] Miyanohara A, Kamizato K, Juhas S, et al. Potent spinal parenchymal AAV9-mediated gene delivery by subpial injection in adult rats and pigs. Mol. Ther. - Methods Clin. Dev. [Internet]. 2016 [cited 2019 Dec 6];3:16046. Available from: https://www.sciencedirect.com/science/article/pii/S2329050117300189?via\%3Dihub\#bib5.

[96] Bravo-Hernandez M, Tadokoro T, Navarro MR, et al. Spinal subpial delivery of AAV9 enables widespread gene silencing and blocks motoneuron degeneration in ALS. Nat. Med. [Internet]. 2020;26:118-130. Available from: http://dx.doi.org/10.1038/s41591-019-0674-1.

[97] Russell S, Bennett J, Wellman JA, et al. Efficacy and safety of voretigene neparvovec (AAV2-hRPE65v2) in patients with RPE65-mediated inherited retinal dystrophy: a randomised, controlled, open-label, phase 3 trial. Lancet (London, England) [Internet]. 2017 [cited 2019 Dec 6];390:849-860. Available from: http://www.ncbi.nlm.nih.gov/pubmed/28712537.

[98] Hoy SM. Onasemnogene Abeparvovec: First Global Approval. Drugs [Internet]. 2019 [cited 2019 
Dec 6];79:1255-1262. Available from: http://www.ncbi.nlm.nih.gov/pubmed/31270752.

[99] Raoul C, Abbas-Terki T, Bensadoun J-C, et al. Lentiviral-mediated silencing of SOD1 through RNA interference retards disease onset and progression in a mouse model of ALS. Nat. Med. [Internet]. 2005 [cited 2019 Dec 9];11:423-428. Available from: http://www.nature.com/articles/nm1207.

[100] Ralph GS, Radcliffe PA, Day DM, et al. Silencing mutant SOD1 using RNAi protects against neurodegeneration and extends survival in an ALS model. Nat. Med. [Internet]. 2005 [cited 2019 Dec 9];11:429-433. Available from: http://www.nature.com/articles/nm1205.

[101] Wu R, Wang H, Xia X, et al. Nerve injection of viral vectors efficiently transfers transgenes into motor neurons and delivers RNAi therapy against ALS. Antioxidants Redox Signal. [Internet]. 2009 [cited 2019 Dec 9];11:1523-1534. Available from: http://www.liebertpub.com/doi/10.1089/ars.2009.2618.

[102] Towne C, Setola V, Schneider BL, et al. Neuroprotection by gene therapy targeting mutant SOD1 in individual pools of motor neurons does not translate into therapeutic benefit in fALS mice. Mol. Ther. [Internet]. 2011 [cited 2019 Dec 11];19:274-283. Available from: http://www.ncbi.nlm.nih.gov/pubmed/21102563.

[103] Foust KD, Salazar DL, Likhite S, et al. Therapeutic AAV9-mediated Suppression of Mutant SOD1 Slows Disease Progression and Extends Survival in Models of Inherited ALS. Mol. Ther. [Internet]. 2013 [cited 2019 Dec 9];21:2148-2159. Available from: https://www.sciencedirect.com/science/article/pii/S1525001616309418.

[104] Towne C, Raoul C, Schneider BL, et al. Systemic AAV6 delivery mediating RNA interference against SOD1: Neuromuscular transduction does not alter disease progression in fALS mice. Mol. Ther. [Internet]. 2008 [cited 2019 Dec 9];16:1018-1025. Available from: http://www.ncbi.nlm.nih.gov/pubmed/18414477.

[105] Borel F, Gernoux G, Cardozo B, et al. Therapeutic rAAVrh10 Mediated SOD1 Silencing in Adult SOD1G93A Mice and Nonhuman Primates. Hum. Gene Ther. [Internet]. 2016 [cited 2019 Dec 11];27:19-31. Available from: http://www.liebertpub.com/doi/10.1089/hum.2015.122. *In this study, a safety trial of SOD1 silencing is conducted in non-human primates, demonstrating a good safety profile, with no immune or off-target side effects.

[106] Gaj T, Ojala DS, Ekman FK, et al. In vivo genome editing improves motor function and extends survival in a mouse model of ALS. Sci. Adv. [Internet]. 2017 [cited 2019 Dec 11];3:eaar3952. Available from: http://www.ncbi.nlm.nih.gov/pubmed/29279867. **This paper described the first attempt to silence SOD1 in ALS mouse models using CRISPR/Cas9 technology.

[107] van Zundert B, Peuscher MH, Hynynen M, et al. Neonatal neuronal circuitry shows hyperexcitable disturbance in a mouse model of the adult-onset neurodegenerative disease amyotrophic lateral sclerosis. J. Neurosci. [Internet]. 2008 [cited 2019 Dec 3];28:10864-10874. Available from: http://www.ncbi.nlm.nih.gov/pubmed/18945894.

[108] van Zundert B, Izaurieta P, Fritz E, et al. Early pathogenesis in the adult< onset neurodegenerative disease amyotrophic lateral sclerosis. J. Cell. Biochem. [Internet]. 2012 [cited 2019 Dec 3];113:3301-3312. Available from: https://onlinelibrary.wiley.com/doi/abs/10.1002/jcb.24234.

[109] Bories C, Amendola J, Lamotte d'Incamps B, et al. Early electrophysiological abnormalities in lumbar motoneurons in a transgenic mouse model of amyotrophic lateral sclerosis. Eur. J.

Neurosci. [Internet]. 2007 [cited 2019 Dec 3];25:451-459. Available from: http://doi.wiley.com/10.1111/j.1460-9568.2007.05306.x.

[110] Pambo-Pambo A, Durand J, Gueritaud J-P. Early Excitability Changes in Lumbar Motoneurons of Transgenic SOD1 ${ }^{\text {G85R }}$ and SOD1 G93A-Low Mice. J. Neurophysiol. [Internet]. 2009 [cited 2019 Dec 3];102:3627-3642. Available from: https://www.physiology.org/doi/10.1152/jn.00482.2009.

[111] Kuo JJ, Siddique T, Fu R, et al. Increased persistent $\mathrm{Na}^{+}$current and its effect on excitability in 
motoneurones cultured from mutant SOD1 mice. J. Physiol. [Internet]. 2005 [cited 2019 Dec 3];563:843-854. Available from: http://doi.wiley.com/10.1113/jphysiol.2004.074138.

[112] Reischauer C, Gutzeit A, Neuwirth C, et al. In-vivo evaluation of neuronal and glial changes in amyotrophic lateral sclerosis with diffusion tensor spectroscopy. NeuroImage. Clin. [Internet]. 2018 [cited 2019 Dec 3];20:993-1000. Available from: http://www.ncbi.nlm.nih.gov/pubmed/30317156.

[113] McCampbell A, Cole T, Wegener AJ, et al. Antisense oligonucleotides extend survival and reverse decrement in muscle response in ALS models. J. Clin. Invest. [Internet]. 2018 [cited 2019 Nov 27];128:3558-3567. Available from: https://www-jci-org.pros.lib.unimi.it:2050/articles/view/99081\#B9.

[114] Chen L, Watson C, Morsch M, et al. Improving the Delivery of SOD1 Antisense Oligonucleotides to Motor Neurons Using Calcium Phosphate-Lipid Nanoparticles. Front. Neurosci. [Internet]. 2017 [cited 2019 Dec 9];11:476. Available from: http://journal.frontiersin.org/article/10.3389/fnins.2017.00476/full.

[115] Miller TM, Kaspar BK, Kops GJ, et al. Virus-delivered small RNA silencing sustains strength in amyotrophic lateral sclerosis. Ann. Neurol. [Internet]. 2005 [cited 2019 Dec 9];57:773-776. Available from: http://doi.wiley.com/10.1002/ana.20453.

[116] Thomsen GM, Gowing G, Latter J, et al. Delayed disease onset and extended survival in the SOD1G93A rat model of amyotrophic lateral sclerosis after suppression of mutant SOD1 in the motor cortex. J. Neurosci. [Internet]. 2014 [cited 2019 Dec 9];34:15587-15600. Available from: http://www.jneurosci.org/content/34/47/15587.short.

[117] Wang H, Ghosh A, Baigude H, et al. Therapeutic gene silencing delivered by a chemically modified small interfering RNA against mutant SOD1 slows amyotrophic lateral sclerosis progression. J. Biol. Chem. [Internet]. 2008 [cited 2019 Dec 9];283:15845-15852. Available from: http://www.ncbi.nlm.nih.gov/pubmed/18367449.

[118] Iannitti T, Scarrott JM, Likhite S, et al. Translating SOD1 Gene Silencing toward the Clinic: A Highly Efficacious, Off-Target-free, and Biomarker-Supported Strategy for fALS. Mol. Ther. Nucleic Acids [Internet]. 2018 [cited 2019 Dec 9];12:75-88. Available from: https://www.sciencedirect.com/science/article/pii/S2162253118300891?via\%3Dihub.

[119] Saito Y, Yokota T, Mitani T, et al. Transgenic small interfering RNA halts amyotrophic lateral sclerosis in a mouse model. J. Biol. Chem. [Internet]. 2005 [cited 2019 Dec 10];280:4282642830. Available from: http://www.ncbi.nlm.nih.gov/pubmed/16221675.

[120] Xia XG, Zhou H, Zhou S, et al. An RNAi strategy for treatment of amyotrophic lateral sclerosis caused by mutant $\mathrm{Cu}, \mathrm{Zn}$ superoxide dismutase. J. Neurochem. [Internet]. 2005 [cited 2019 Dec 9];92:362-367. Available from: http://doi.wiley.com/10.1111/j.1471-4159.2004.02860.x.

[121] Toro Cabrera G, Mueller C. Design of shRNA and miRNA for Delivery to the CNS. 2016 [cited 2019 Dec 11]. p. 67-80. Available from: http://link.springer.com/10.1007/978-1-4939-3271-9_5.

[122] Wang H, Yang B, Qiu L, et al. Widespread spinal cord transduction by intrathecal injection of rAAV delivers efficacious RNAi therapy for amyotrophic lateral sclerosis. Hum. Mol. Genet. [Internet]. 2014 [cited 2019 Dec 9];23:668-681. Available from: http://www.ncbi.nlm.nih.gov/pubmed/24108104.

[123] Dirren E, Aebischer J, Rochat C, et al. SOD1 silencing in motoneurons or glia rescues neuromuscular function in ALS mice. Ann. Clin. Transl. Neurol. [Internet]. 2015 [cited 2019 Dec 11];2:167-184. Available from: http://doi.wiley.com/10.1002/acn3.162. *In this study, SOD1 silencing is attempted selectively in motor neurons or astrocytes: astrocyte-specific silencing normalized motor parameters, thus supporting a critical role of the astroglial expression of mutated SOD1 in the decline of neuromuscular function.

[124] Stoica L, Todeasa SH, Cabrera GT, et al. Adeno-associated virus-delivered artificial microRNA 
extends survival and delays paralysis in an amyotrophic lateral sclerosis mouse model. Ann. Neurol. [Internet]. 2016 [cited 2019 Dec 11];79:687-700. Available from: http://doi.wiley.com/10.1002/ana.24618.

[125] Wang L, Yi F, Fu L, et al. CRISPR/Cas9-mediated targeted gene correction in amyotrophic lateral sclerosis patient iPSCs. Protein Cell [Internet]. 2017 [cited 2019 Dec 11];8:365-378. Available from: http://www.ncbi.nlm.nih.gov/pubmed/28401346. 


\section{Figure Legend}

Figure 1. Endogenous pathways may be exploited to achieve therapeutic gene silencing. Primary miRNAs (Pri< miRNAs) are transcribed from miRNA genes and cleaved by Drosha into hairpin precursors (pre< miRNAs). Pre< miRNAs are transported to the cytoplasm by exportin-5 and subsequently cleaved by Dicer, giving rise to miRNAs. miRNAs engage with the RNA< induced silencing complex (RISC) to promote RNA degradation or translational arrest. Vector< delivered synthetic miRNAs (smiRNAs) and short hairpin RNAs (shRNAs) need to penetrate the nucleus to enter the upstream miRNA pathway. Small interfering RNAs (siRNAs) and single < stranded siRNAs (ss< miRNAs) act directly in the cytoplasm. Antisense oligonucleotides (ASOs) complementary to nuclear pre < mRNAs or cytoplasmic mRNAs exploit the RNAse-mediated pathway, binding to complementary sequences to induce their degradation. This process may occur both in the nucleus and in the cytoplasm. CRISPR/Cas9 acts on double-stranded DNA, causing breakage at target sites in the genome. 
Table. 1. Preclinical in vivo and clinical studies of SOD1 silencing.

This table focuses on animal and human studies of SOD1 silencing, highlighting the impact on survival in terms of percentage increase. Abbreviations: AV, adenovirus, AAV; adeno-associated virus; CMV, cytomegalovirus; ICV, Intracerebroventricular; LV, lentivirus; $\mathrm{MO}$, morpholino oligonucleotides; $\mathrm{P}$, postnatal age; RGP, rabies-glycoprotein-pseudotyped.

\begin{tabular}{|c|c|c|c|c|c|c|c|}
\hline Intervention & Model & $\begin{array}{l}\text { Stud } \\
\text { y } \\
\text { samp } \\
\text { le } \\
\text { size }\end{array}$ & $\begin{array}{l}\text { Start of } \\
\text { treatme } \\
\text { nt }\end{array}$ & $\begin{array}{l}\text { Delivery } \\
\text { route }\end{array}$ & $\begin{array}{l}\text { Increas } \\
\text { e in } \\
\text { survival }\end{array}$ & $\begin{array}{l}\text { Reference } \\
\text {, Year }\end{array}$ & $\begin{array}{l}\text { Current } \\
\text { stage }\end{array}$ \\
\hline \multicolumn{8}{|c|}{ Antisense oligonucleotides } \\
\hline SOD1 -r141692 & hSOD1-G93A-tg-Rat & 12 & P65 & $\mathrm{ICV}$ & $8 \%$ & $\begin{array}{l}\text { Smith et al., } \\
2006\end{array}$ & \multirow[t]{2}{*}{ l } \\
\hline Bare-MO & hSOD1-G93A-tg-mice & 11 & P85 & $\begin{array}{l}\mathrm{ICV}, \\
\text { intraven } \\
\text { ous }\end{array}$ & $\begin{array}{l}+19-2 \\
1 \text { days }\end{array}$ & $\begin{array}{l}\text { Nizzardo et } \\
\text { al., } 2016\end{array}$ & \\
\hline $\begin{array}{l}\text { Bare-MO, } \\
\text { Modified-MO }\end{array}$ & hSOD1-G93A-tg-mice & N/A & P0, P3, P6 & $\begin{array}{l}\mathrm{ICV}, \\
\text { intraperit } \\
\text { oneal }\end{array}$ & $\begin{array}{l}\text { N/A } \\
\text { (tissue } \\
\text { analys } \\
\text { is) }\end{array}$ & - & l \\
\hline Modified-MO & hSOD1-G93A-tg-mice & N/A & P120 & $\begin{array}{l}\text { Intraven } \\
\text { ous }\end{array}$ & $\begin{array}{l}\text { N/A } \\
\text { (tissue } \\
\text { analys } \\
\text { is) }\end{array}$ & - & l \\
\hline $\begin{array}{l}\text { Tofersen (ISIS } \\
\text { 333611, BIIB067, } \\
\text { IONIS SOD1Rx) }\end{array}$ & $\begin{array}{l}\text { Randomized, } \\
\text { placebo-controlled, } \\
\text { phase } 1 \text { trial }\end{array}$ & 21 & Symptomatic & $\begin{array}{l}\text { Intrathec } \\
\text { al }\end{array}$ & \begin{tabular}{l|} 
Follo \\
w-up \\
study \\
now \\
ongoin \\
g
\end{tabular} & $\begin{array}{l}\text { Miller at al., } \\
2013\end{array}$ & $\begin{array}{l}\text { Follow-up } \\
\text { study now } \\
\text { ongoing } \\
\text { (NCT030 } \\
70119 \text { ) }\end{array}$ \\
\hline $\begin{array}{l}\text { Next-generation } \\
\text { ASOs }\end{array}$ & hSOD1-G93A-tg-rats & 53 & P65 & $\begin{array}{l}\text { Intrathec } \\
\text { al }\end{array}$ & $\begin{array}{l}+40 \\
\text { days }\end{array}$ & $\begin{array}{l}\text { McCampbell } \\
\text { et al., } 2018\end{array}$ & / \\
\hline- & hSOD1-G93A-tg-mice & 60 & $\mathrm{P} 80 / \mathrm{P} 120$ & ICV & $\begin{array}{l}+50 \\
\text { days }\end{array}$ & - & / \\
\hline \multicolumn{8}{|c|}{ Rna interference: shRNAs/siRNAs } \\
\hline RGP-LV-shRNA & hSOD1-G93A-tg-mice & 6 & P7 & $\begin{array}{l}\text { Intramusc } \\
\text { ular }\end{array}$ & $77 \%$ & $\begin{array}{l}\text { Ralph et } \\
\text { al., } 2005\end{array}$ & l \\
\hline Lenti-H1-shRNA & hSOD1-G93A-tg-mice & 6 & $\mathrm{P} 40$ & $\begin{array}{l}\text { Intraspina } \\
1\end{array}$ & $0 \%$ & $\begin{array}{l}\text { Raoul et } \\
\text { al., } 2005\end{array}$ & / \\
\hline $\begin{array}{l}\text { AAV2<GFP< } \\
\text { siRNA }\end{array}$ & hSOD1-G93A-tg-mice & 10 & $\mathrm{P} 45$ & $\begin{array}{l}\text { Intramusc } \\
\text { ular }\end{array}$ & $\begin{array}{l}\text { Increase } \\
\mathrm{d} \\
\text { preservat } \\
\text { ion of } \\
\text { grip } \\
\text { strength } \\
\text { in the } \\
\text { injected } \\
\text { side }\end{array}$ & $\begin{array}{l}\text { Miller et } \\
\text { al., } 2005\end{array}$ & l \\
\hline $\begin{array}{l}\text { Transgenic } \\
\text { U6-shRNA }\end{array}$ & $\begin{array}{l}\text { antiSOD1-shRNA-hSOD1- } \\
\text { G93A-tg-mice }\end{array}$ & -6 & - & - & $>90 \%$ & $\begin{array}{l}\text { Saito et al., } \\
2005\end{array}$ & / \\
\hline $\begin{array}{l}\text { Transgenic CMV } \\
\text { shRNA }\end{array}$ & $\begin{array}{l}\text { hSOD1-G93A-tg-mice and } \\
\text { hSOD1-G93A-Gur-tg-mice }\end{array}$ & 9 & $\begin{array}{l}\text { Embryo } \\
\text { nic stage }\end{array}$ & $\begin{array}{l}\text { Injection } \\
\text { into }\end{array}$ & $27 \%$ & $\begin{array}{l}\text { Xia et al., } \\
2006\end{array}$ & / \\
\hline
\end{tabular}




\begin{tabular}{|c|c|c|c|c|c|c|c|}
\hline & & & & $\begin{array}{l}\text { pronuclei } \\
\text { of } \\
\text { fertilized } \\
\text { eggs }\end{array}$ & & & \\
\hline $\begin{array}{l}\text { Transgenic } \\
\text { U6-shRNA }\end{array}$ & $\begin{array}{l}\text { antiSOD1-shRNA-hSOD1- } \\
\text { G93A-tg-mice }\end{array}$ & 5 & - & - & $\begin{array}{l}\text { Prolonga } \\
\text { tion of } \\
\text { disease } \\
\text { duration } \\
\end{array}$ & $\begin{array}{l}\text { Yokota et } \\
\text { al., } 2007\end{array}$ & I \\
\hline Modified sirRNA & hSOD1-G93A-tg-mice & 6 & P85 & $\begin{array}{l}\text { Intratheca } \\
1\end{array}$ & $6 \%$ & $\begin{array}{l}\text { Wang et } \\
\text { al., } 2008\end{array}$ & I \\
\hline AAV6-H1-shRNA & hSOD1-G93A-tg-mice & 3 & P35-42 & $\begin{array}{l}\text { Intraveno } \\
\text { us }\end{array}$ & 0 & $\begin{array}{l}\text { Towne et } \\
\text { al., } 2008\end{array}$ & I \\
\hline AV-U6-shRNA & hSOD1-G93A-tg-mice & 23 & P94 & $\begin{array}{l}\text { Injection } \\
\text { into } \\
\text { sciatic } \\
\text { nerve }\end{array}$ & $8 \%$ & $\begin{array}{l}\text { Wu et al., } \\
2009\end{array}$ & I \\
\hline AAV6-H1-shRNA & hSOD1-G93A-tg-mice & 8 & P1-P15 & $\begin{array}{l}\text { Intramusc } \\
\text { ular }\end{array}$ & 0 & $\begin{array}{l}\text { Towne et } \\
\text { al., } 2011\end{array}$ & I \\
\hline AAV9-H1-shRNA & hSOD1-G93A-tg-mice & 8 & P1 & $\begin{array}{l}\text { Intraveno } \\
\text { us }\end{array}$ & $39 \%$ & $\begin{array}{l}\text { Foust et } \\
\text { al., } 2013\end{array}$ & 1 \\
\hline- & - & 6 & $\mathrm{P} 21$ & - & $30 \%$ & - & \\
\hline & - & 6 & P85 & - & $23 \%$ & - & \\
\hline AAV9-H1-shRNA & hSOD1-G93A-tg-Rat & 14 & P70 & $\begin{array}{l}\text { Intracorti } \\
\text { cal }\end{array}$ & $12 \%$ & $\begin{array}{l}\text { Thomsen } \\
\text { et al., } 2014\end{array}$ & I \\
\hline scAAV9-H1-shRNA & hSOD1-G93A-tg-mice & 9 & $\begin{array}{l}\text { P1 } \\
\text { (Pre-ons } \\
\text { et) }\end{array}$ & $\begin{array}{l}\text { Intratheca } \\
1 \text { via } \\
\text { cisterna } \\
\text { magna }\end{array}$ & $42 \%$ & $\begin{array}{l}\text { Iannitti et } \\
\text { al., } 2018\end{array}$ & I \\
\hline & hSOD1-G93A-tg-mice & 15 & $\begin{array}{l}\text { P40 } \\
\text { (Disease } \\
\text { onset) }\end{array}$ & $\begin{array}{l}\text { Intratheca } \\
1 \text { via } \\
\text { cisterna } \\
\text { magna }\end{array}$ & +19 days & & \\
\hline $\begin{array}{l}\text { AAV9-shRNA- } \\
\text { SOD1 }\end{array}$ & hSOD1-G37R-tg-mice & 17 & $\begin{array}{l}\text { P120 } \\
\text { (Pre-On } \\
\text { set) }\end{array}$ & $\begin{array}{l}\text { Spinal } \\
\text { subpial } \\
\text { (cervical } \\
+ \text { lumbar) }\end{array}$ & $\begin{array}{l}+81 \\
\text { days }\end{array}$ & $\begin{array}{l}\text { Bravo-Her } \\
\text { nandez et } \\
\text { al., } 2020\end{array}$ & 1 \\
\hline & & 4 & $\begin{array}{l}\text { P348 } \\
\text { (Mid-dis } \\
\text { ease) }\end{array}$ & - & $\begin{array}{l}\text { No } \\
\text { further } \\
\text { disease } \\
\text { progressi } \\
\text { on }\end{array}$ & - & I \\
\hline \multicolumn{8}{|c|}{ RNA interference: miRNAs } \\
\hline AAVrh10-CBA-miR & hSOD1-G93A-tg-mice & 37 & P55-60 & $\begin{array}{l}\text { Intratheca } \\
1 \text { via } \\
\text { lumbar } \\
\text { puncture }\end{array}$ & $11 \%$ & $\begin{array}{l}\text { Wang et } \\
\text { al., } 2014\end{array}$ & 7 \\
\hline AAV6-CMV-miR & hSOD1-G93A-tg-mice & 10 & $\mathrm{P} 2$ & ICV & $26 \%$ & $\begin{array}{l}\text { Dirren et } \\
\text { al., } 2015\end{array}$ & I \\
\hline AAV9-GFAP-miR & - & 9 & $\mathrm{P} 2$ & - & $14 \%$ & - & \\
\hline AAVrh10-CBA-miR & hSOD1-G93A-tg-mice & N/A & P56-68 & $\begin{array}{l}\text { Intraveno } \\
\text { us }\end{array}$ & $20 \%$ & $\begin{array}{l}\text { Borel et } \\
\text { al., } 2016\end{array}$ & 7 \\
\hline AAVrh10-U6-miR & - & N/A & - & - & $21 \%$ & - & \\
\hline AAV9-CBA-miR & hSOD1-G93A-tg-mice & 22 & P0-1 & ICV & $50 \%$ & $\begin{array}{l}\text { Stoica et } \\
\text { al., } 2016\end{array}$ & 1 \\
\hline \multicolumn{8}{|l|}{ CRISPR/Cas9 } \\
\hline AAV9-CMV-SaCas9 & hSOD1-G93A-tg-mice & 10 & $\mathrm{P} 0-1$ & Intraveno & $+28-30$ & Gaj et al., & 1 \\
\hline
\end{tabular}




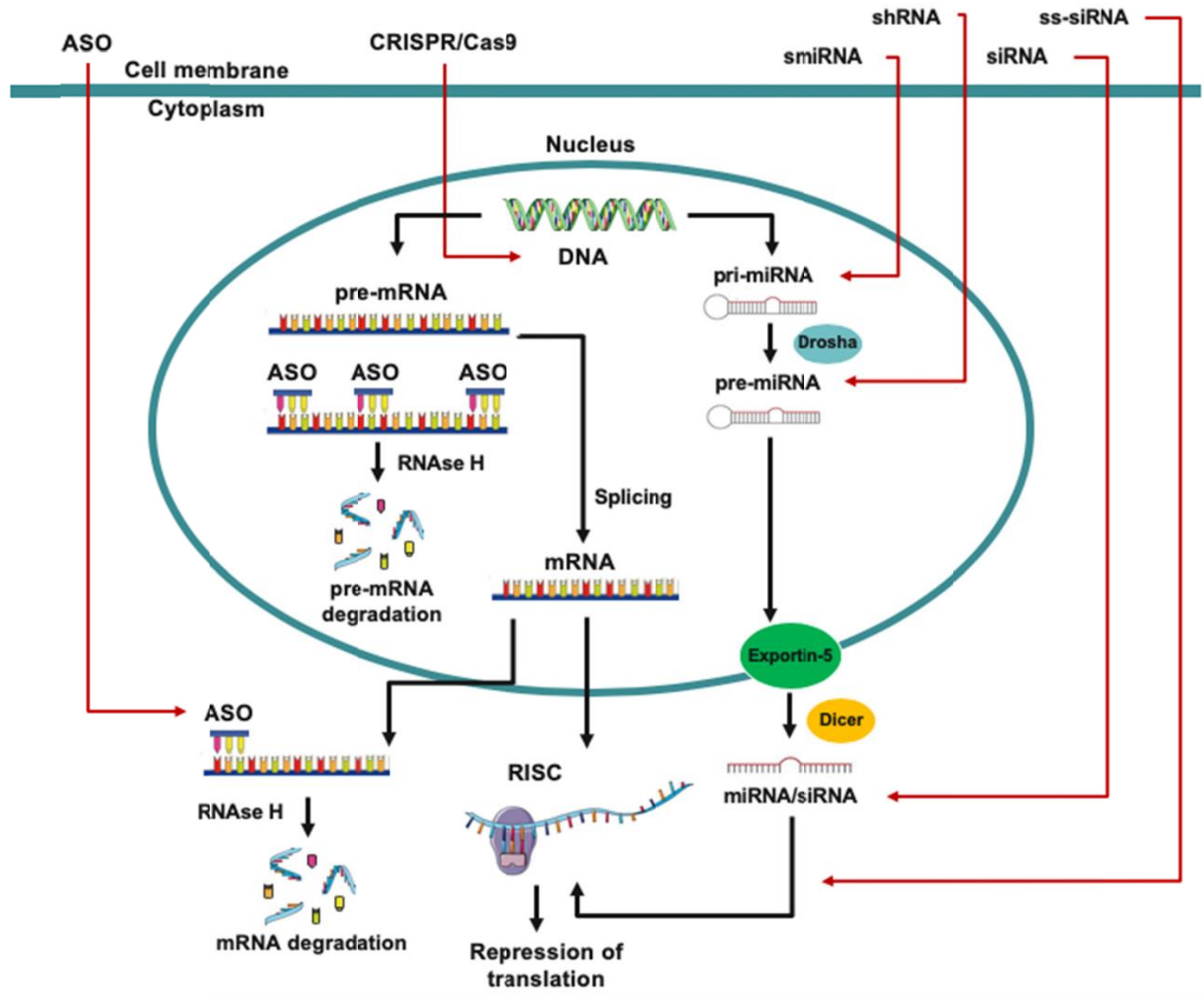

Figure 1 